\title{
A novel role of DNA polymerase $\lambda$ in translesion synthesis in conjunction with DNA polymerase $\zeta$
}

\author{
Jung-Hoon Yoon, Debashree Basu, Karthi Sellamuthu, Robert E Johnson, Satya Prakash, Louise Prakash (1)
}

\begin{abstract}
By extending synthesis opposite from a diverse array of DNA lesions, DNA polymerase (Pol) $\zeta$ performs a crucial role in translesion synthesis (TLS). In yeast and cancer cells, Rev1 functions as an indispensable scaffolding component of Pol $\zeta$ and it imposes highly errorprone TLS upon Polל. However, for TLS that occurs during replication in normal human cells, Rev1 functions instead as a scaffolding component of Pols $\eta, \mathrm{l}$, and $\kappa$ and Rev1-dependent TLS by these Pols operates in a predominantly error-free manner. The lack of Rev1 requirement for Pol $\zeta$ function in TLS in normal cells suggested that some other protein substitutes for this Rev1 role. Here, we identify a

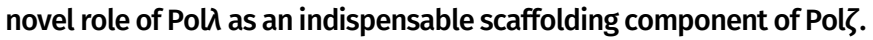
TLS studies opposite a number of DNA lesions support the conclusion

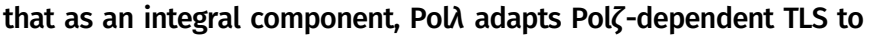
operate in a predominantly error-free manner in human cells, essential for genome integrity and cellular homeostasis.
\end{abstract}

DOI 10.26508/Isa.202000900 | Received 31 August 2020 | Revised 11 December 2020 | Accepted 6 January 2021 | Published online 29 January 2021

\section{Introduction}

DNA lesions that escape removal by excision repair processes block the progression of replication forks (RFs). By promoting proficient replication through DNA lesions, translesion synthesis (TLS) DNA polymerases (Pols) prevent the collapse of RFs stalled at DNA lesion sites and protect against chromosomal instability and tumorigenesis (Yoon et al, 2019b).

Biochemical, structural, and genetic studies have indicated that TLS Pols have specialized functions in replicating through DNA lesions, and that their active sites are adapted for accommodating specific types of DNA lesions (Prakash et al, 2005). For example, because of its unique ability to accommodate two template residues in its active site, Poln can proficiently replicate through the UVinduced covalently linked cyclobutane pyrimidine dimer (CPD) by forming a Watson-Crick (W-C) base pair between each pyrimidine of the CPD and an incoming nucleotide (nt) (Johnson et al, 1999, 2000b; Masutani et al, 1999; Washington et al, 2000, 2003; Biertumpfel et al, 2010; Silverstein et al, 2010). Whereas replication through certain DNA lesions can be performed by the action of just one Pol, such as by Poln opposite CPDs, replication through a vast array of other DNA lesions requires the sequential action of two TLS Pols, wherein one Pol inserts a nt opposite the DNA lesion site from which another Pol extends synthesis (Johnson et al, 2000a; Prakash \& Prakash, 2002; Prakash et $\mathrm{al}, 2005)$. Biochemical studies have shown that Pol $\zeta$ functions specifically in the extension step of TLS and is proficient in extending synthesis past a large variety of DNA lesions (Johnson et al, 2000a, 2001; Haracska et al, 2001; Nair et al, 2006).

In yeast, Rev1 functions as an indispensable scaffolding component of Pol $\zeta$, and its ability to associate-via its C terminus-with Pol $\zeta$ is essential for Pol $\zeta$ 's ability to function in TLS in yeast cells, and TLS by Rev1/Pol Complex operates in a highly mutagenic manner (Baynton et al, 1999; Nelson et al, 2000; Haracska et al, 2001; Gibbs et al, 2005; Acharya et al, 2006). In normal human cells, however, Rev1 does not function together with Polろ; instead, Rev1 functions as an indispensable scaffolding component of the Y-family DNA Pols $\eta, 1$, and $\mathrm{k}$ (Yoon et al, 2015). Moreover, Rev1dependent TLS by $Y$-family Pols operates in a much more error-free manner in human cells than would be expected from the low fidelity of the purified Pols. We have suggested previously that as a scaffolding component, Rev1 effects the assembly of a multiprotein complex wherein the fidelity of the TLS Poln, l, $k$, or Rev1 is enhanced (Yoon et al, 2019a, 2018, 2017, 2015).

The lack of Rev1 requirement for Pol function in TLS that operates during replication in normal human cells (Yoon et al, 2015) suggested that some other protein substitutes for Rev1 in this role. Here we identify a role for Pol $\lambda$, an X-family DNA Pol, in Pol $\zeta$-dependent TLS in normal human cells. Previous studies have implicated Pol $\lambda$ in short patch base excision repair and non-homologous end joining (Garcia-Diaz et al, 2001, 2005; Lee et al, 2004; Braithwaite et al, 2005a, 2005b, 2010; Pryor et al, 2015) and purified Pol $\lambda$ can catalyze synthesis across an abasic site and a thymine glycol (Maga et al, 2002; Belousova et al, 2010). Our evidence that Pol $\lambda$ functions as an essential scaffolding component of Pol $\zeta$ adds a novel di-

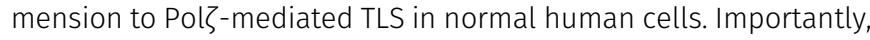
in contrast to the highly error-prone Rev1/Pol $\zeta$-mediated TLS that is observed in yeast (Lawrence \& Christensen, 1978, 1979; Lawrence et al, 1984; Gibbs et al, 2005; Acharya et al, 2006) or in TLS that occurs

Department of Biochemistry and Molecular Biology, University of Texas Medical Branch, Galveston, TX, USA

Correspondence: loprakas@utmb.edu

Debashree Basu's present address is Ultragenyx Pharmaceuticals, Inc., Woburn, MA, USA 
in mammalian cells during gap repair (Yoon et al, 2015), or in cancer cells (Doles et al, 2010; Xie et al, 2010; Xu et al, 2013), TLS dependent upon $\mathrm{Pol} \lambda / \mathrm{Pol} \zeta$ operates in a predominantly error-free manner in human cells. We discuss the implications of adoption of Pol $\lambda$ as an

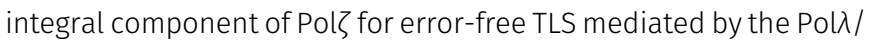
Polろ complex.

\section{Results}

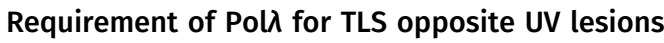

To analyze the role of Pol $\lambda$ in TLS, we used the SV40 duplex plasmid in which bidirectional replication initiates from an origin of replication and TLS through the DNA lesion carried on the template for leading or lagging strand replication is determined by the frequency of blue colonies among the total $\mathrm{Kan}^{+}$colonies (Yoon et al, $2009,2010 b)$. As determined in previous studies, the genetic control of TLS determined by using this plasmid system reflects the TLS mechanisms that operate during genomic replication. For example, using the EBV origin-based plasmid, where plasmid replication is controlled by the same processes that govern cellular replication, we showed that the same TLS Pols are required for replication through UV lesions in the EBV-based plasmid as in the SV40-based plasmid (Yoon et al, 2012). In other studies we have provided evidence that the Pols identified to have a role in TLS opposite UV lesions in plasmid studies are also required for RF progression through UV lesions in primary cells (Yoon et al, 2019b). Although not all the complexities in the genomic context such as topology, chromatin state, or epigenetic modifications will be reflected in the plasmid system, the basic TLS mechanisms remain the same in the genomic context as in the plasmid system (Yoon et al, 2019b).

\section{TLS opposite cis-syn TT dimer}

In our previous analyses of the genetic control of TLS opposite UV lesions, we have shown that TLS through a cis-syn TT dimer operates via a Poln-dependent error-free pathway or via an alternative Pol $\theta$-dependent pathway which acts in an error-prone manner (Yoon et al, 2019b). Because of its proficient ability to insert nts opposite both the 3'T and 5'T of the dimer and to subsequently extend synthesis, Poln alone conducts TLS through the cis-syn TT dimer. In the Pol $\theta$-dependent pathway, however, following nt insertion opposite the $3^{\prime} T$ of the dimer by Pol $\theta$, either Polk or Pol $\zeta$ is required to insert a nt opposite the $5^{\prime} T$ and extend subsequent synthesis (Yoon et al, 2019b) (see also Fig 1A). A role of Pol $\lambda$ in TLS in conjunction with $\mathrm{Pol} \zeta$ implies that an epistatic relationship would exist between them.

As shown in Table 1, TLS opposite a cis-syn TT dimer carried on the leading strand template in nucleotide excision repair defective XPA cells occurs with a frequency of $\sim 38 \%$. TLS frequency is reduced to $\sim 18 \%$ and $\sim 21 \%$ in cells depleted for Poln or Pol $\theta$, respectively. Depletion of Polk or the Rev3 or Rev7 subunit of Polろ reduces TLS frequency to $\sim 30 \%$ and a similar reduction in TLS frequency occurs in cells depleted for Pol $\lambda$. Our results that co-depletion of Polk with Pol $\lambda$ reduces TLS frequency to $18 \%$ conform with a role for Polk and
A

B

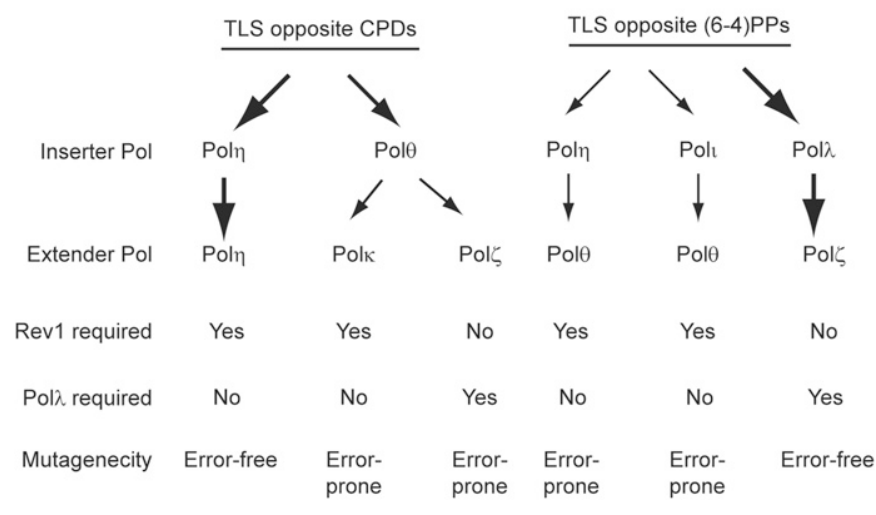

Figure 1. TLS pathways for replication through UV lesions.

(A) TLS pathways for replication through cyclobutane pyrimidine dimers (CPDS). Poln replicates through CPDs in an error-free manner. Pol $\theta$ functions in inserting nts opposite the $3^{\prime} \mathrm{T}$ or $3^{\prime} \mathrm{C}$ of a CPD in the error-prone TLS pathways dependent upon Polk or Polろ for extension of synthesis. As a scaffolding component, Rev1

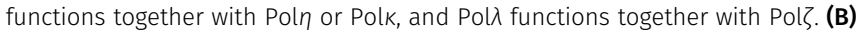
TLS pathways for replication through (6-4)PPs. Pol $\theta$ extends synthesis from the nts inserted by Pol $\eta$ or Polı opposite the $3^{\prime} T$ or $3^{\prime} \mathrm{C}$ of the (6-4) photoproduct and these pathways promote error-prone TLS. After nt insertion opposite the (6-4) lesion by Pol$\lambda$, Pol $\zeta$ would extend synthesis from the nt inserted by Pol $\lambda$. The Pol $\lambda /$ Pol $\zeta$ pathway conducts error-free TLS through (6-4) PPs. The thickness of the arrows depicts the relative contribution of TLS Pols to lesion bypass.

Pold in alternative TLS pathways, and the observation that TLS frequency remains the same in cells co-depleted for Rev3 with Pol $\lambda$ as in cells depleted for either Pol alone, supports a role for Pol $\lambda$ in the same TLS pathway as Polろ. Furthermore, the observation that TLS frequency remains the same in cells co-depleted for Pol $\theta$ with Pol $\lambda(\sim 19 \%)$ as in cells depleted for Pol $\theta$ alone is congruent with epistasis of Pol $\theta$ over Pol $\lambda$, similar to the epistasis of Pol $\theta$ over Pol $\zeta$ we reported previously (Yoon et al, 2019b). In addition, the reduction in TLS frequency to $\sim 12 \%$ in cells co-depleted for Pol $\eta$ and Pol $\lambda$ concurs with their role in alternative TLS pathways. Because of the requirement of Rev1 for Poln- and Polk-dependent TLS pathways, TLS by both these pathways is inhibited in Rev1-depleted cells, and only the Pol $\zeta$ pathway remains functional (Yoon et al, 2015). Our results that TLS frequency is reduced to a residual level of $\sim 4 \%$ in cells co-depleted for Rev 1 and Pol $\lambda$ (Table 1), similar to those seen upon co-depletion of Rev1 with Polろ (Yoon et al, 2015), support

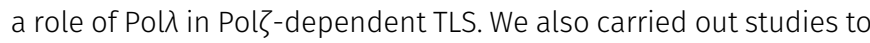
analyze Pol$\lambda$ 's role in TLS opposite a cis-syn TT dimer carried on the lagging strand template in the duplex plasmid (Table 1). The epistatic effects of Rev3 and Pol $\lambda$ depletion on TLS frequency and a drastic reduction in TLS frequency in cells co-depleted for Rev1 and Pol $\lambda$ add further evidence for a role of Pol $\lambda$ in TLS in conjunction with Pol $\zeta$ in a pathway that functions independently of Rev1dependent TLS pathways (Table 1 and Fig 1A).

In addition, we analyzed Pol $\lambda^{\prime}$ 's role in TLS opposite a cis-syn TT dimer in XPV HFs defective in Pol $\eta$, and in Pol$\lambda^{-/-}$MEFs (Table 2). In XPV cells, TLS opposite a cis-syn TT dimer occurs with a frequency of $\sim 11 \%$ and TLS frequency is reduced to $5 \%$ in cells depleted for Pol $\zeta$ (Rev3 or Rev7), Pol $\lambda$, or co-depleted for both Pols (Table 2). In Pol $\lambda^{-1-}$ MEFs, TLS opposite a cis-syn TT dimer occurs at a frequency of $24 \%$, 
Table 1. The effects of siRNA knockdowns of Pol $\lambda$ and other TLS Pols on replicative bypass of a cis-syn TT dimer or a (6-4) TT photoproduct carried on the leading or lagging DNA strand template in XPA human fibroblasts.

\begin{tabular}{|c|c|c|c|c|c|c|c|}
\hline \multirow[b]{2}{*}{ UV lesion } & \multirow[b]{2}{*}{ SiRNA } & \multicolumn{3}{|l|}{ Leading strand } & \multicolumn{3}{|l|}{ Lagging strand } \\
\hline & & Number of $\mathrm{Kan}^{+}$colonies & $\begin{array}{l}\text { Number of blue } \\
\text { colonies among } \\
\mathrm{Kan}^{+}\end{array}$ & $\operatorname{TLS}(\%)^{a}$ & $\begin{array}{l}\text { Number of } \mathrm{Kan}^{+} \\
\text {colonies }\end{array}$ & $\begin{array}{l}\text { Number of blue } \\
\text { colonies among } \\
\text { Kan }^{+}\end{array}$ & $\operatorname{TLS}(\%)^{\mathrm{a}}$ \\
\hline \multirow{13}{*}{ cis-syn TT dimer } & NC & 534 & 205 & 38.4 & 465 & 152 & 32.7 \\
\hline & Poln & 406 & 72 & 17.7 & 389 & 62 & 15.9 \\
\hline & Pol $\theta$ & 412 & 86 & 20.9 & 394 & 60 & 15.2 \\
\hline & Polk & 528 & 158 & 29.9 & 412 & 89 & 21.6 \\
\hline & Rev3 & 436 & 127 & 29.1 & 408 & 81 & 19.9 \\
\hline & Rev7 & 512 & 146 & 28.5 & 570 & 124 & 21.8 \\
\hline & Pold & 508 & 144 & 28.3 & 394 & 90 & 22.8 \\
\hline & Rev1 & 446 & 66 & 14.8 & 366 & 45 & 12.3 \\
\hline & Polk + Pold & 316 & 56 & 17.7 & 543 & 86 & 15.8 \\
\hline & Rev3 + Pold & 566 & 162 & 28.6 & 612 & 124 & 20.3 \\
\hline & Pol $\theta+\operatorname{Pol} \lambda$ & 306 & 59 & 19.3 & 405 & 65 & 16.0 \\
\hline & Poln + Pold & 562 & 66 & 11.7 & 587 & 56 & 9.5 \\
\hline & Rev1 + Pold & 408 & 18 & 4.4 & 422 & 15 & 3.6 \\
\hline \multirow{9}{*}{$(6-4) \pi \mathrm{PP}$} & NC & 630 & 215 & 34.1 & 562 & 174 & 31.0 \\
\hline & Pold & 386 & 65 & 16.8 & 482 & 71 & 14.7 \\
\hline & Rev3 & 426 & 73 & 17.1 & 685 & 100 & 14.6 \\
\hline & Rev7 & 506 & 82 & 16.2 & 541 & 84 & 15.5 \\
\hline & Rev3 + Pold & 401 & 67 & 16.7 & 612 & 94 & 15.4 \\
\hline & Rev1 & 402 & 64 & 15.9 & 366 & 68 & 18.6 \\
\hline & Pol $\theta$ & 468 & 84 & 17.9 & 556 & 88 & 15.8 \\
\hline & Rev1 + Pold & 545 & 28 & 5.1 & 504 & 24 & 4.8 \\
\hline & Pol $\theta+\operatorname{Pol} \lambda$ & 668 & 37 & 5.5 & 635 & 30 & 4.7 \\
\hline
\end{tabular}

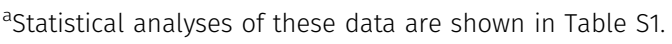

and TLS frequency remains the same in Rev3 depleted Pol$\lambda^{-1-}$ MEFs, whereas Poln depletion reduces TLS frequency to $\sim 11 \%$. (Table 2 ).

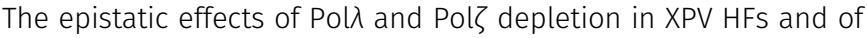
Pol $\zeta$ depletion in Pol$\lambda^{-1-}$ MEFs add further evidence for a role of

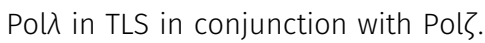

\section{TLS opposite (6-4) TT photoproduct}

In previous studies, we provided evidence that TLS opposite a (6-4) TT photoproduct occurs via two error-prone pathways dependent upon either Poln/Pol $\theta$ or Polı/pol $\theta$ in which after nt insertion opposite the $3^{\prime} T$ of the photoproduct by Poln or Polı, Pol $\theta$ would insert a nt opposite the 5'T and extend synthesis further (Yoon et al, 2019b) (Fig 1B). As a scaffolding component, Rev1 is required for TLS by both Pol $\eta$ and Polı. Pol $\zeta$ functions in an alternative pathway independent of Pol $\theta$ and Rev1, and it promotes error-free TLS through (6-4) PPs (Yoon et al, 2019b, 2015) (Fig 1B). Because purified Pol $\zeta$ lacks the ability to insert a nt opposite the 3'T of (6-4) TT but extends synthesis from the $\mathrm{nt}$ inserted opposite the $3^{\prime} \mathrm{T}$ of the photoproduct (Johnson et al, 2000a, 2001), we have previously suggested that another TLS
Pol, which had remained to be identified, would insert a nt opposite the 3'T of (6-4) TT from which Polろ would extend synthesis (Yoon et al, 2010b). In the sections below, we provide evidence for such a role of Pold.

As shown in Table 1, in XPA HFs, TLS opposite a (6-4) TT PP carried on the leading strand template occurs with a frequency of $\sim 34 \%$, and TLS frequency declines to $17 \%$ in cells depleted either for Pol $\lambda$, Rev3, or Rev7, or co-depleted for Rev3 and Pol $\lambda$ The epistatic re-

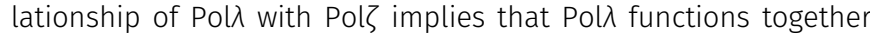
with Pol in TLS at (6-4) PPs. In cells depleted for Rev1 or Pol $\theta$, TLS opposite (6-4) TT PP occurs at a frequency of $\sim 16-18 \%$ and codepletion of Pold with either Rev1 or Pol $\theta$ confers a drastic reduction in TLS to a level of $\sim 5 \%$ (Table 1), similar to the reduction in TLS that occurs upon the depletion of Pol $\zeta$ with Rev1 or with Pol $\theta$ (Yoon et al, 2019b, 2015). These data are congruent with a role of Pol $\lambda$ in conjunction with Pol $\zeta$ in a pathway that operates independently of TLS dependent upon Rev1 and Pol $\theta$. We additionally verified these conclusions for TLS opposite a (6-4) TT PP carried on the lagging strand template in XPA HFs (Table 1). Also, the epistatic relationship between Pol $\lambda$ and $\mathrm{Pol} \zeta$ observed in XPV HFs or Pol $\lambda^{-1-}$ MEFs (Table 2) adds further evidence for a role of Pol $\lambda$ in promoting 
Table 2. Effects of siRNA knockdowns of Poli and other TLS Pols on replicative bypass of a cis-syn TT dimer or a (6-4) TT photoproduct carried on the leading DNA strand template in XPV HFs or in WT or Pol$\lambda^{-I-}$ MEFs.

\begin{tabular}{|c|c|c|c|c|c|}
\hline Cells & UV lesion & SIRNA & Number of $\mathrm{Kan}^{+}$colonies & Number of blue colonies among $\mathrm{Kan}^{+}$ & $\operatorname{TLS}(\%)^{\mathrm{a}}$ \\
\hline \multirow{6}{*}{ XPV HFS } & \multirow{6}{*}{ cis-syn TT dimer- } & NC & 312 & 34 & 10.9 \\
\hline & & Rev3 & 308 & 17 & 5.5 \\
\hline & & Rev7 & 321 & 18 & 5.6 \\
\hline & & Pold & 274 & 16 & 5.8 \\
\hline & & Rev3 + Pold & 332 & 19 & 5.7 \\
\hline & & Rev7 + Pold & 294 & 16 & 5.4 \\
\hline \multirow{6}{*}{ XPV HFS } & \multirow{6}{*}{$(6-4) T T P P$} & NC & 405 & 62 & 15.3 \\
\hline & & Pol $\theta$ & 294 & 23 & 7.8 \\
\hline & & Rev3 & 348 & 25 & 7.2 \\
\hline & & Pold & 355 & 26 & 7.3 \\
\hline & & Rev3 + Pold & 304 & 25 & 8.2 \\
\hline & & $\operatorname{Pol} \theta+\operatorname{Pol} \lambda$ & 278 & 10 & 3.6 \\
\hline WT MEFS & cis-syn TT dimer & NC & 376 & 120 & 31.9 \\
\hline \multirow{3}{*}{ Pold $\lambda^{-/-}$MEFs } & & NC & 432 & 104 & 24.1 \\
\hline & & Rev3 & 295 & 70 & 23.7 \\
\hline & & Poln & 248 & 27 & 10.9 \\
\hline WT MEFS & $(6-4) \mathrm{TT} P \mathrm{PP}$ & NC & 422 & 128 & 30.3 \\
\hline \multirow{4}{*}{ Pold $\lambda^{-1-}$ MEFs } & & $\mathrm{NC}$ & 390 & 57 & 14.6 \\
\hline & & Rev3 & 276 & 42 & 15.2 \\
\hline & & Rev1 & 388 & 10 & 2.6 \\
\hline & & Pol $\theta$ & 408 & 11 & 2.7 \\
\hline
\end{tabular}

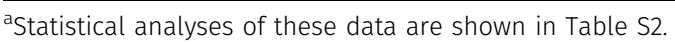

TLS through (6-4) TT photoproduct via a Polろ-dependent pathway that operates independently of Rev1 and Pol $\theta$ (Fig 1B).

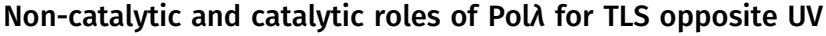 lesions}

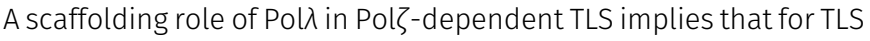
opposite CPDs where Pol $\zeta$ would extend synthesis from the nt inserted opposite the $3^{\prime} T$ or $3^{\prime} \mathrm{C}$ by Pol $\theta$, its DNA polymerase activity will not be required. For TLS opposite (6-4) PPs, however, Pol $\lambda$ 's DNA polymerase activity could be required for nt insertion opposite the $3^{\prime} \mathrm{T}$ or $3^{\prime} \mathrm{C}$ of the photoproduct because the polymerase for such a role has not been identified previously (Yoon et al, 2010b, 2019b). To establish that Pold polymerase activity was not required for TLS opposite CPDs and to determine if its polymerase function was required for TLS opposite (6-4) PP, we analyzed the effects of the D427A, D429A mutations which inactivate Pol $\lambda$ 's DNA polymerase activity. As shown in Table 3, TLS opposite a cis-syn TT dimer in Pol $\lambda^{-1-}$ MEFs carrying the vector plasmid occurs with a frequency of $\sim 24 \%$ and TLS frequency rises to $\sim 32 \%$ in Pol $\lambda^{-1-}$ MEFs expressing WT

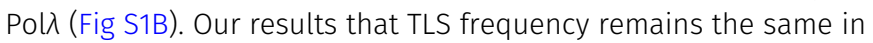
Pol $\lambda^{-1-}$ MEFs, which express the Pol $\lambda$ catalytic mutant protein (Fig $\mathrm{S} 1 \mathrm{~B}$ ) as in cells expressing WT Pol (Table 3 ) validate the conclusion that Pol $\lambda$ 's polymerase activity is not required for TLS opposite a cis- syn TT dimer. Thus, for TLS opposite CPDs, only the non-catalytic scaffolding role of Pol $\lambda$ is required.

TLS opposite a (6-4) TT photoproduct in Pol $\lambda^{-1-}$ MEFs carrying the vector plasmid occurs with a frequency of $\sim 15 \%$ and TLS frequency rises to $\sim 30 \%$ in Pol$\lambda^{-1-}$ MEFs expressing WT Pol $\lambda$ (Table 3). Our observation that TLS frequency remains at $\sim 14 \%$ in Pol$\lambda^{-/-}$MEFs which express the Pol$\lambda$ catalytic mutant provides strong evidence

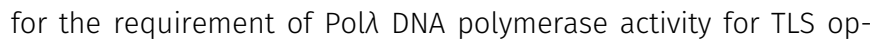
posite (6-4) photoproduct (Table 3). Thus, for TLS opposite (6-4) PPS, both the DNA synthetic and the non-catalytic scaffolding roles of Pold would be required.

\section{Biochemical analysis of Pol $\lambda$ 's role in TLS opposite (6-4) TT photoproduct}

Because the DNA synthesis activity of Pold is required for TLS opposite the (6-4) photoproduct in human cells, we examined

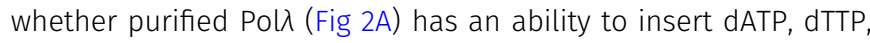
dGTP, or dCTP opposite the 3'T of a (6-4) TT photoproduct. As shown in Fig 2B, on undamaged DNA, Pol $\lambda$ inserts dATP opposite both the $3^{\prime} T$ and 5 'T efficiently such that almost all the DNA substrate has been used up, and in the presence of 4 dNTPs, it extends synthesis further. Remarkably, we find that Pol $\lambda$ inserts dATP opposite the 3'T as well as the 5'T of the (6-4) photoproduct, albeit less efficiently. In 


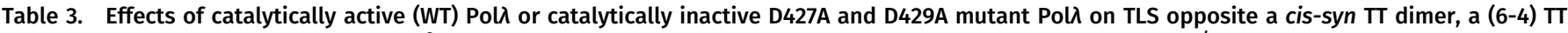
photoproduct, a thymine glycol, or a 1, $\mathrm{N}^{6}$-ethenodeoxyadenosine, carried on the leading strand template in Pol $\lambda^{-1-}$ MEFs.

\begin{tabular}{|c|c|c|c|c|}
\hline DNA lesion & Vector expressing & Number of $\mathrm{Kan}^{+}$colonies & Number of blue colonies among $\mathrm{Kan}^{+}$colonies & $\operatorname{TLS}(\%)^{\mathrm{a}}$ \\
\hline \multirow{3}{*}{ cis-syn TT dimer } & No Pol入 (control) & 355 & 87 & 24.5 \\
\hline & WT Pold & 348 & 111 & 31.9 \\
\hline & Mutant Pold & 409 & 124 & 30.3 \\
\hline \multirow{3}{*}{$(6-4) \Pi \mathrm{PP}$} & No Pol入 (control) & 308 & 46 & 14.9 \\
\hline & WT Pold & 316 & 95 & 30.1 \\
\hline & Mutant Pold & 286 & 40 & 14.0 \\
\hline \multirow{3}{*}{$\operatorname{Tg}$} & No Pol入 (control) & 446 & 46 & 10.3 \\
\hline & WT Pold & 395 & 84 & 21.3 \\
\hline & Mutant Pold & 361 & 80 & 22.2 \\
\hline \multirow{3}{*}{$\varepsilon \mathrm{dA}$} & No Pol入 (control) & 311 & 34 & 10.9 \\
\hline & WT Polג & 405 & 82 & 20.2 \\
\hline & Mutant Polג & 286 & 62 & 21.7 \\
\hline
\end{tabular}

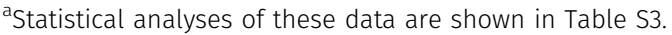

the presence of all 4 dNTPS, Pol $\lambda$ inserts a nt opposite the $3^{\prime} T$ and $5^{\prime} T$ of the photoproduct and then inserts a nt opposite the next nucleotide as well (Fig 2B). Thus, Pold performs synthesis opposite (6-4) TT photoproduct, and does so correctly by inserting an A. As expected from the lack of requirement of Pold DNA synthesis activity for TLS opposite a cis-syn TT dimer in vivo (Table 3), purified Pold shows no TLS activity opposite the dimer (Fig S2).

\section{Evidence for Polג's involvement in error-prone TLS opposite CPDs and in error-free TLS opposite (6-4) photoproducts}

In normal cells, TLS opposite a cis-syn $\pi$ dimer generates 2\% mutant TLS products which harbor a change at the 3'T or 5'T (Table 4).

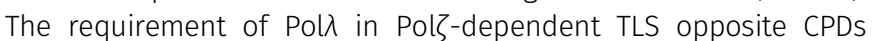

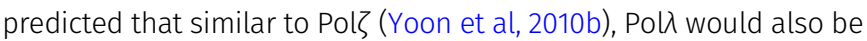
required for mutagenic TLS opposite CPDs. We find that opposite a cis-syn TT dimer carried on the leading or lagging strand template, the incidence of mutagenic TLS is reduced to $0.7 \%$ in Pol $\lambda$ depleted cells (Table 4), similar to the reduction that occurs upon Pol $\zeta$ depletion (Yoon et al, 2010b). This result is congruent with a role of Pold in Polל-dependent error-prone TLS opposite a cis-syn TT dimer.

TLS opposite a (6-4) TT photoproduct also generates $~ 2 \%$ mutational TLS products which harbor a change at the $3^{\prime} T$ or $5^{\prime} \mathrm{T}$ of the

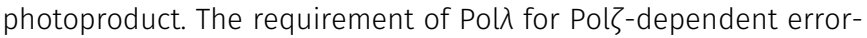
free TLS opposite (6-4) PPS predicted that the frequency of mutational TLS products would rise in Pol $\lambda$-depleted cells; accordingly, we find that the frequency of mutant TLS products increases to $\sim-5 \%$ in Pol $\lambda$-depleted cells (Table 4), similar to that seen upon Polろ depletion (Yoon et al, 2010b).

Next, we extended mutational analyses to the cll gene integrated into the genome of big blue mouse embryonic fibroblasts (BBMEFs) where we could analyze the effect of Pol $\lambda$ depletion on UV-induced mutations resulting from TLS opposite CPDs and (6-4) PPs formed at the various $\mathrm{TT}, \mathrm{TC}$, and $\mathrm{CC}$ dipyrimidine sites. The spectrum of mutations induced by UV and other DNA damaging agents in the cll gene resembles that determined from sequence analyses of endogenous chromosomal genes or from whole-genome sequence analyses (You et al, 2001; You \& Pfeifer, 2001; Besaratinia \& Pfeifer, 2006; Alexandrov et al, 2013; Martincorena et al, 2015). To examine UV-induced mutations resulting from TLS opposite CPDs, the (6-4) PPs are selectively removed from the genome by expressing a (6-4) PP photolyase gene in the BBMEF cell line (You et al, 2001). In this cell line, the frequency of spontaneous mutations in the $\mathrm{cll}$ gene is $\sim 16 \times 10^{-5}$, and this frequency remains the same in cells depleted for Pol入 (Table 5). In UV-irradiated $\left(5 \mathrm{~J} / \mathrm{m}^{2}\right)$ cells exposed to photoreactivating light to activate (6-4) PP removal, mutation frequency rises to $\sim 46 \times 10^{-5}$ (Table 5). Thus, the additional increase of $\sim 30 \times$ $10^{-5}$ in mutation frequency results from mutagenic TLS opposite
A

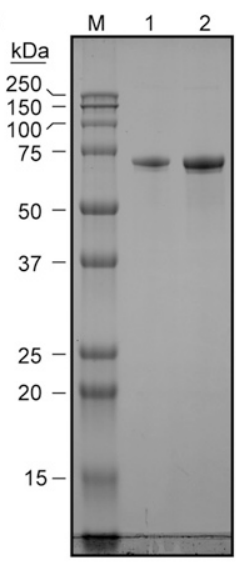

B

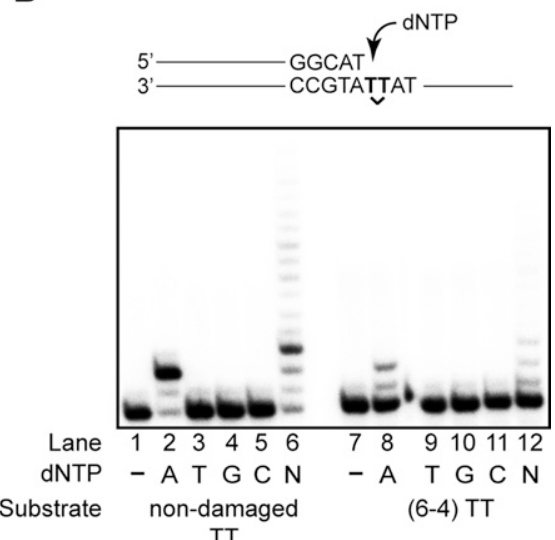

Figure 2. DNA synthesis opposite (6-4) TT photoproduct by purified Polג. (A) SDS-PAGE of purified full-length Pol $\lambda$. Human DNA polymerase $\lambda$ was purified from yeast cells as described in the Materials and Methods section. Lane M, $5 \mu \mathrm{l}$ precision plus protein standard (Bio-Rad). Lane 1, $0.75 \mu \mathrm{g}$ Pol $\lambda$. Lane 2, $1.5 \mu \mathrm{g}$ Polג. Molecular weight marker sizes are given on the left. (B) Nucleotide incorporation opposite an undamaged TT or opposite 6-4 (TT) photoproduct. Reactions were carried out as described in the Materials and Methods section and included either a single deoxynucleotide triphosphate (dGTP, dATP, dTTP, or $\mathrm{dCTP}$ ) or all $4 \mathrm{dNTPS}$. A schematic representation of the substrate is shown on top. 
Table 4. Effects of siRNA knockdown of Poli on mutation frequencies and nucleotides inserted opposite a cis-syn TT dimer or a (6-4) TT photoproduct carried on the leading or lagging strand DNA template in nucleotide excision repair-defective XPA human fibroblasts.

\begin{tabular}{|c|c|c|c|c|c|c|c|c|c|}
\hline \multirow[b]{2}{*}{ DNA lesion } & \multirow[b]{2}{*}{ Lesion containing DNA strand } & \multirow[b]{2}{*}{ SIRNA } & \multicolumn{6}{|l|}{ Nucleotide inserted } & \multirow{2}{*}{$\begin{array}{l}\text { Mutation } \\
\text { frequency \% }\end{array}$} \\
\hline & & & $\begin{array}{l}\text { \# of } \mathrm{Kan}^{+} \text {blue } \\
\text { colonies sequenced }\end{array}$ & A & G & C & $\mathbf{T}$ & Other $^{a}$ & \\
\hline \multirow{6}{*}{ cis-syn TT dimer } & \multirow{3}{*}{ Leading } & \multirow{2}{*}{ NC } & \multirow{2}{*}{$334(7)^{b}$} & \multirow{2}{*}{327} & \multirow{2}{*}{$4\left(3^{\prime} T\right)^{c}$} & \multirow{2}{*}{-} & $2\left(5^{\prime} \mathrm{T}\right)$ & & \multirow{2}{*}{2.1} \\
\hline & & & & & & & $1\left(3^{\prime} T\right)$ & & \\
\hline & & Pold & $402(3)$ & 399 & $3\left(3^{\prime} \mathrm{T}\right)$ & - & - & - & 0.7 \\
\hline & \multirow{3}{*}{ Lagging } & \multirow{2}{*}{ NC } & \multirow{2}{*}{$375(10)$} & \multirow{2}{*}{365} & $4\left(5^{\prime} \mathrm{T}\right)$ & \multirow{2}{*}{-} & $1\left(5^{\prime} \mathrm{T}\right)$ & \multirow{2}{*}{-} & \multirow{2}{*}{2.7} \\
\hline & & & & & $2\left(3^{\prime} T\right)$ & & $3\left(3^{\prime} \mathrm{T}\right)$ & & \\
\hline & & Pold & $318(2)$ & 316 & $2\left(3^{\prime} \mathrm{T}\right)$ & - & - & - & 0.6 \\
\hline \multirow{8}{*}{ (6-4) TT photoproduct } & \multirow{4}{*}{ Leading } & \multirow{2}{*}{ NC } & \multirow{2}{*}{$342(8)$} & \multirow{2}{*}{334} & $3\left(5^{\prime} \mathrm{T}\right)$ & \multirow{2}{*}{-} & \multirow{2}{*}{$2\left(3^{\prime} T\right)$} & \multirow{2}{*}{1} & \multirow{2}{*}{2.3} \\
\hline & & & & & $2\left(3^{\prime} T\right)$ & & & & \\
\hline & & \multirow{2}{*}{ Pold } & \multirow{2}{*}{$347(15)$} & \multirow{2}{*}{332} & $1\left(5^{\prime} \mathrm{T}\right)$ & \multirow{2}{*}{$6\left(3^{\prime} \mathrm{T}\right)$} & \multirow{2}{*}{$4\left(3^{\prime} \mathrm{T}\right)$} & \multirow{2}{*}{2} & \multirow{2}{*}{4.3} \\
\hline & & & & & $2\left(3^{\prime} T\right)$ & & & & \\
\hline & & & & & $2\left(5^{\prime} T\right)$ & & & & \\
\hline & & INC & $304(7)$ & $3 / 1$ & $2\left(3^{\prime} T\right)$ & & $2(3 \quad 1)$ & 1 & 1.8 \\
\hline & Lassing & DIR & 270 & 30 & $4\left(5^{\prime} \mathrm{T}\right)$ & T) & $2\left(\partial^{\prime} T\right)$ & 0 & \\
\hline & & Pols & $320(10)$ & 304 & $3\left(3^{\prime} T\right)$ & $4\left(\begin{array}{lll}3 & 1\end{array}\right)$ & 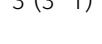 & 2 & 3.0 \\
\hline
\end{tabular}

${ }^{a}$ Mutations at the flanking site.

${ }^{b}$ Numbers of colonies where TLS occurred by insertion of a nucleotide other than an A are shown in parenthesis.

'The site where mutation occurred, $3^{\prime} T$ or $5^{\prime} T$ of the UV lesion is indicated in parenthesis.

CPDs formed at the dipyrimidine sites in the cll gene. The highly elevated UV-induced mutation frequency $\left(\sim 90 \times 10^{-5}\right)$ in Poln-depleted cells and the greatly reduced mutation frequency $\left(\sim 17 \times 10^{-5}\right)$ in Pol $\theta$-depleted cells results from the requirement of Pol $\eta$ for error-free TLS and from the indispensability of Pol $\theta$ for error-prone TLS opposite CPDs, respectively (Table 5). Mutation frequency in UVirradiated cells depleted for Pold declines to the same level as in Rev3-depleted cells and remains the same in cells co-depleted for Pol $\lambda$ and Rev3 $\left(\sim 32 \times 10^{-5}\right)$, indicating epistasis (Table 5$)$. In addition, the evidence that co-depletion of Rev1 and Pol $\lambda$ reduces mutation frequency in UV-irradiated cells to a level near to that in unirra-

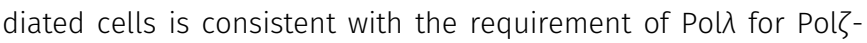
dependent error-prone TLS opposite CPDs that operates independently of Rev1-dependent TLS (Table 5 and Fig 1A).

To examine UV mutations resulting from TLS opposite (6-4) PPS, CPDs are selectively removed from the genome by expressing a CPD photolyase gene in the BBMEF cell line (You et al, 2001). In this cell line, spontaneous mutations in the cll gene occur at a frequency of $\sim 18 \times 10^{-5}$ and Pold depletion has no perceptible effect on this frequency (Table 5). In UV-irradiated $\left(5 \mathrm{~J} / \mathrm{m}^{2}\right)$ cells exposed to photoreactivating light to activate the CPD photolyase, mutation frequency increases to $\sim 29 \times 10^{-5}$, and in cells depleted for Rev1 or Pol $\theta$, mutation frequency declines to the same level $\left(\sim 18 \times 10^{-5}\right)$ as in unirradiated cells (Table 5), consistent with the requirement of Rev1 and Pol $\theta$ for Poln- and Polı-dependent error-prone TLS opposite (6-4) PPs (Fig 1B). As expected from the requirement of Pol $\lambda$ for Pol $\zeta$-dependent error-free TLS, UV-induced mutation frequency rises to $\sim 40 \times 10^{-5}$ in cells depleted for Pol $\lambda$ or Rev3, or co-depleted for both Pols (Table 5). The epistatic effects of Pol $\lambda$ and Rev3 depletions on error-free TLS opposite (6-4) PPS as well as the observation that UV-induced mutation frequency declines to near spontaneous levels in cells co-depleted for Pol $\lambda$ together with Rev1 or with Pol $\theta$ (Table 5) provide confirmatory evidence for the in-

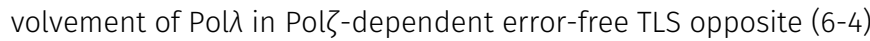
PPs in a pathway that provides an alternative to the error-prone pathway in which Poln or Polı function together with Rev1 and require Pol $\theta$ for the extension step of TLS (Fig 1B).

In BBMEFs expressing no photolyase, UV-induced mutations resulting from TLS opposite both CPDs and (6-4) PPS would accumulate in the cll gene. In this cell line, spontaneous mutations occur at a frequency of $\sim 15 \times 10^{-5}$ and mutation frequency increases to $\sim 55 \times 10^{-5}$ upon UV treatment ( $5 \mathrm{~J} / \mathrm{m}^{2}$ ) (Table 5). In UV irradiated cells, Pol入 depletion reduces mutation frequency to the same level $\left(\sim 35 \times 10^{-5}\right)$ as occurs upon Rev 3 depletion, consistent with their contribution to errorprone TLS opposite CPDS which account for a large majority of UVinduced mutations ( 80\%) (Pfeifer, 1997; Yoon et al, 2000; You et al, 2001).

UV-induced $C>T$ and $C C>T$ signature mutations resulting from mutagenic TLS through CPDs accumulate in the cll gene at mutational hot spots located at 11 dipyrimidine sequences, \#1 to \#11 in WT cells (Yoon et al, 2009). In Rev3 depleted BBMEFs, mutational hot spots at positions \#1, $\# 2, \# 3$, and \#6 remain, whereas the mutational hot spots at other positions are abrogated (Fig 3A). Previously, we provided evidence that in their role in extending synthesis from the nt inserted opposite the $3^{\prime}$ pyrimidine of the CPDs by another Pol, Polk generates a different spectrum of hot spot mutations than Pol (Yoon et al, 2009); hence the spectrum of hot spot mutations in Pol $\zeta$ depleted cells results from Polk's role in TLS and vice versa. Our observation that the spectrum of mutational hot spots generated by Pol $\lambda$ depletion is nearly identical to the pattern in Rev3 
Table 5. UV-induced mutation frequencies in the cll gene in BBMEF cells expressing a (6-4) PP photolyase, cyclobutane pyrimidine dimer (CPD) photolyase, or no photolyase and treated with siRNA for Poll or other TLS Pols.

\begin{tabular}{|c|c|c|c|c|}
\hline Photolyase & SIRNA & $U^{a}$ & Photoreactivation $^{\text {b }}$ & Mutation frequency ${ }^{c}\left(\times 10^{-5}\right)$ \\
\hline \multirow{10}{*}{ (6-4) PP photolyase } & NC & - & + & $16.1 \pm 0.7$ \\
\hline & Pold & - & + & $16.8 \pm 0.7$ \\
\hline & NC & + & + & $45.9 \pm 1.9$ \\
\hline & Poln & + & + & $88.7 \pm 1.7$ \\
\hline & Pol $\theta$ & + & + & $17.5 \pm 1.1$ \\
\hline & Pold & + & + & $30.1 \pm 1.0$ \\
\hline & Rev3 & + & + & $31.5 \pm 1.6$ \\
\hline & Rev1 & + & + & $58.2 \pm 2.7$ \\
\hline & Rev3 + Pold & + & + & $31.8 \pm 1.1$ \\
\hline & Rev1 + Poll & + & + & $20.1 \pm 1.5$ \\
\hline \multirow{10}{*}{ CPD photolyase } & NC & - & + & $17.9 \pm 1.2$ \\
\hline & Pold & - & + & $19.1 \pm 1.1$ \\
\hline & NC & + & + & $28.9 \pm 1.0$ \\
\hline & Rev1 & + & + & $18.4 \pm 1.6$ \\
\hline & Pol $\theta$ & + & + & $18.4 \pm 1.2$ \\
\hline & Pold & + & + & $40.9 \pm 1.2$ \\
\hline & Rev3 & + & + & $39.1 \pm 2.4$ \\
\hline & Rev3 + Pold & + & + & $39.6 \pm 1.2$ \\
\hline & Rev1 + Pold & + & + & $20.4 \pm 1.6$ \\
\hline & Pol $\theta+$ Pold & + & + & $21.8 \pm 1.4$ \\
\hline \multirow{5}{*}{ pNeo vector (no photolyase) } & NC & - & + & $14.8 \pm 1.0$ \\
\hline & Pold & - & + & $15.0 \pm 1.3$ \\
\hline & NC & + & + & $55.5 \pm 1.9$ \\
\hline & Pold & + & + & $35.0 \pm 1.0$ \\
\hline & Rev3 & + & + & $36.8 \pm 2.9$ \\
\hline
\end{tabular}

$a_{5} \mathrm{~J} / \mathrm{m}^{2}$ of UVC (254 $\left.\mathrm{nm}\right)$ light.

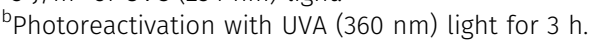

${ }^{c}$ Data are represented as mean \pm SEM. Mean mutation frequencies and standard error of the mean were calculated from four independent experiments.

depleted cells (Fig 3A) adds further evidence that for TLS opposite CPDs, Pol $\lambda$ functions together with Pol $\zeta$ in the error-prone pathway that operates independently of the Polk-dependent error-prone pathway.

Mutagenic TLS through (6-4) PPs generates mutational hot spots in the cll gene at position \#s1-5 (Yoon et al, 2010b). All these hot spots remain in Rev3 depleted cells, and Pol $\lambda$ depletion generates the same spectrum of hot spot mutations (Fig 3B). The persistence of all these hot spots in Rev3 or Pol $\lambda$ depleted cells is consistent with the

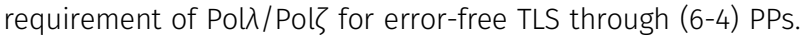

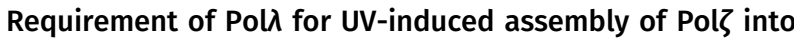 replication foci}

The requirement of Pol $\lambda$ as a scaffolding component of Pol $\zeta$ suggests that Pol$\lambda$ is targeted to RFs stalled at DNA lesion sites in conjunction

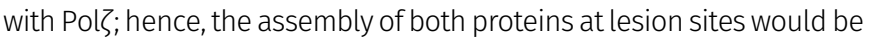
interdependent. To examine this, we expressed Flag-Pold in HFs and analyzed the frequency of Flag-Pol $\lambda$ foci-containing cells. We find that only $3 \%$ of unirradiated cells contain Flag-Pol $\lambda$ foci, whereas upon UV irradiation $15 \%$ of cells contain Flag-Pol $\lambda$ foci (Fig 4A). Our observation that the UV-induced increase in the frequency of Flag-Pol $\lambda$ focicontaining cells does not occur if Rev3 or Rev7 are depleted, indicates that Pol$\zeta$ is required for Pol $\lambda$ assembly into foci (Fig 4A). Conversely, the result that the UV-induced increase in the frequency of Rev7 focicontaining cells is ablated upon Pol $\lambda$ depletion conforms with the requirement of Pol $\lambda$ for Pol $\zeta$ assembly into foci (Fig 4B). The interdependence of Pol $\lambda$ and Pol $\zeta$ for foci formation suggests that Pol $\lambda$ and Pol $\zeta$ exist together in a physical complex in human cells and that this complex assembles at RFs stalled at UV lesions. As expected from the role of Pol $\lambda / P o l \zeta$ in promoting TLS through UV lesions via pathways that operate independently of Rev1/Poln-dependent TLS, depletion of Poln or Rev1 had no effect on UV-induced assembly of Pol $\lambda$ into foci (Fig 4A); and conversely, depletion of Pol $\lambda$ conferred no impairment in UV-induced assembly of Poln into foci (Fig 4C). 
A

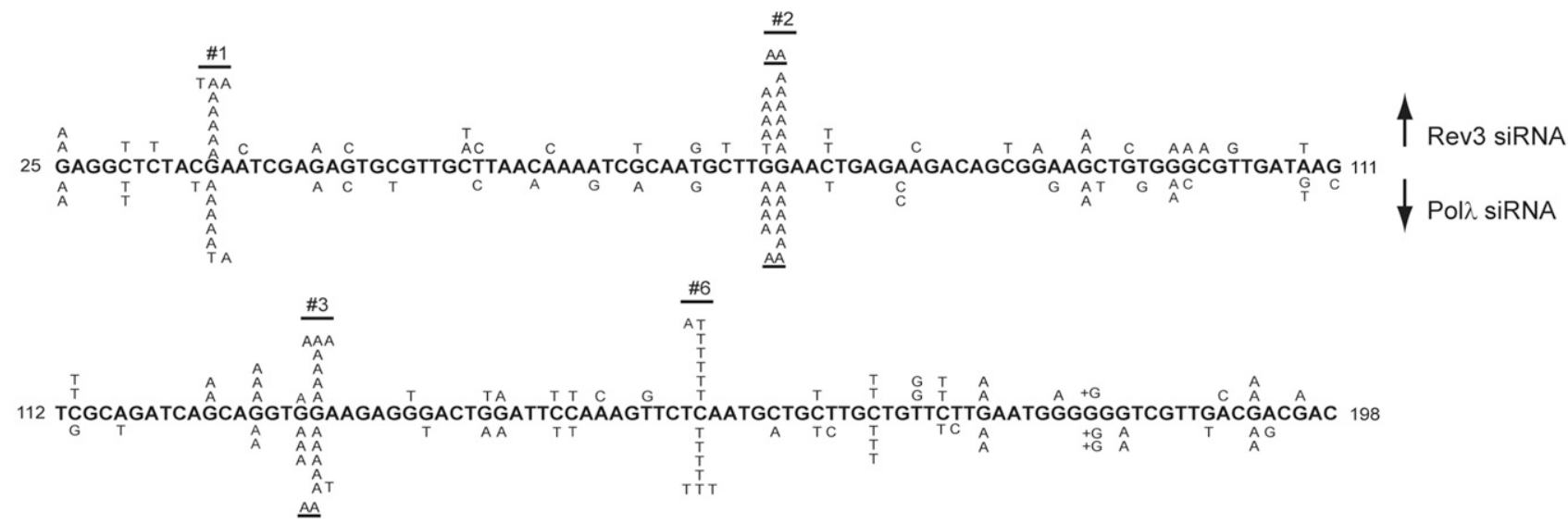

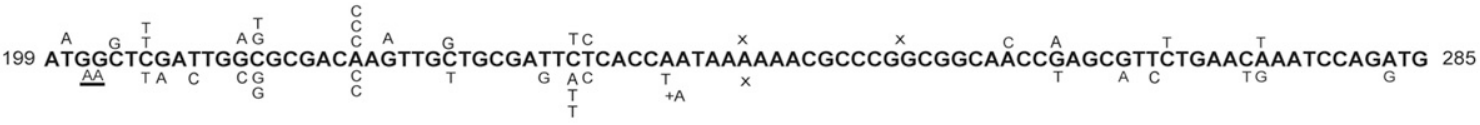

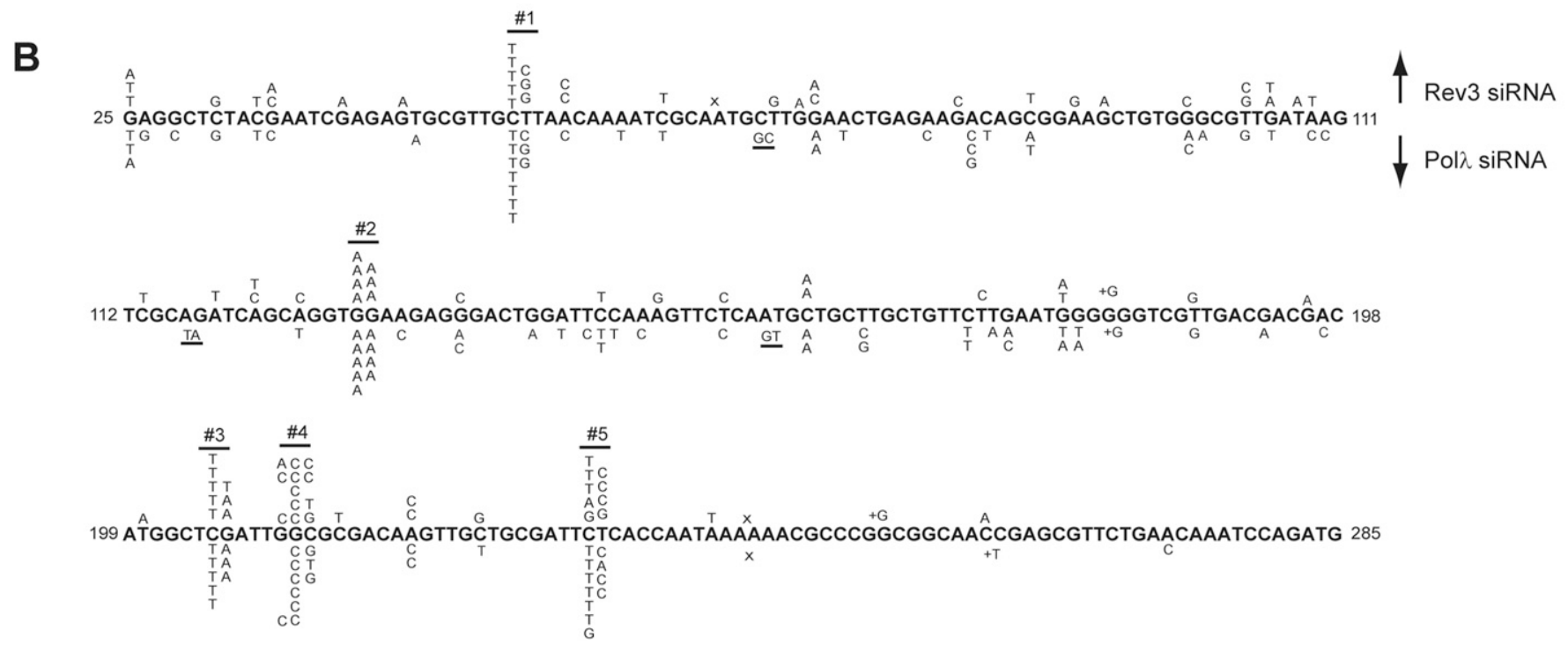

Figure 3. Effects of Pold depletion on UV-induced mutational spectra in the cll gene in BBMEFs.

(A) UV-induced $\left(5 \mathrm{~J} / \mathrm{m}^{2}\right)$ mutational spectra resulting from TLS through cyclobutane pyrimidine dimers (CPDs) in BBMEFs expressing (6-4) PP photolyase. Mutational spectra in Rev3-depleted cells are shown above the sequence and in Pol $\lambda$ depleted cells are shown below the sequence. Whereas TLS through CPDs in WT cells generates hot spots at position \#s 1-11 in the cll gene, only hot spots at position \#s 1, 2, 3, and 6 remain in Rev3- or Pol $\lambda$-depleted cells. (B) UV-induced (5 J/m²) mutational spectra resulting from TLS through (6-4) PPs in BBMEF cells expressing CPD photolyase. Mutational spectra in Rev3 depleted cells are shown above the sequence and in Pol $\lambda$ depleted cells are shown below the sequence. The positions of UV-induced hot spots \#1-5 are indicated.

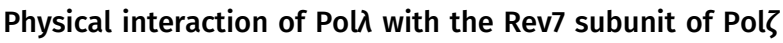

Pold is a 575-residue polypeptide comprised of an N-terminal BRCT domain followed by a proline-rich region and a C-terminal domain that has DNA polymerase activity (Fig 5A). In the Rev1-Polろ complex, the C-terminal region of Rev1 physically interacts with the Rev7 subunit of Polろ (Murakumo et al, 2001; Kikuchi et al, 2012). To determine whether Pol $\lambda$ also interacts physically with Rev7, we carried out pull-down assays in which full-length Pol $\lambda$ was incubated with GST-Rev7 conjugated to glutathione sepharose beads. The observation that Pold co-elutes with GST-Rev7 indicated that the two proteins interact physically (Fig 5B). Although Pol $\lambda$ 's BRCT domain is essential for its role in non-homologous end joining (Lee et al, 2004; Nick McElhinny et al, 2005), this domain is not required for physical interaction of Pol $\lambda$ with Rev7, as N-terminally deleted Pol $\lambda$-NTD coelutes with GST-Rev7 (Fig 5B). The specificity of Pol $\lambda$ interaction with Rev7 was confirmed by ascertaining the lack of Pol $\lambda$ binding to GST alone (Fig 5B).

Our results that in chromatin fractions isolated from UV-irradiated HFs, Polh co-immunoprecipitates (co-IPs) with Rev7 and that the level of their interaction increases in response to UV irradiation add further evidence

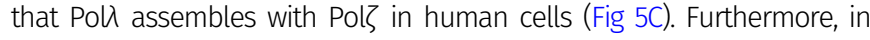



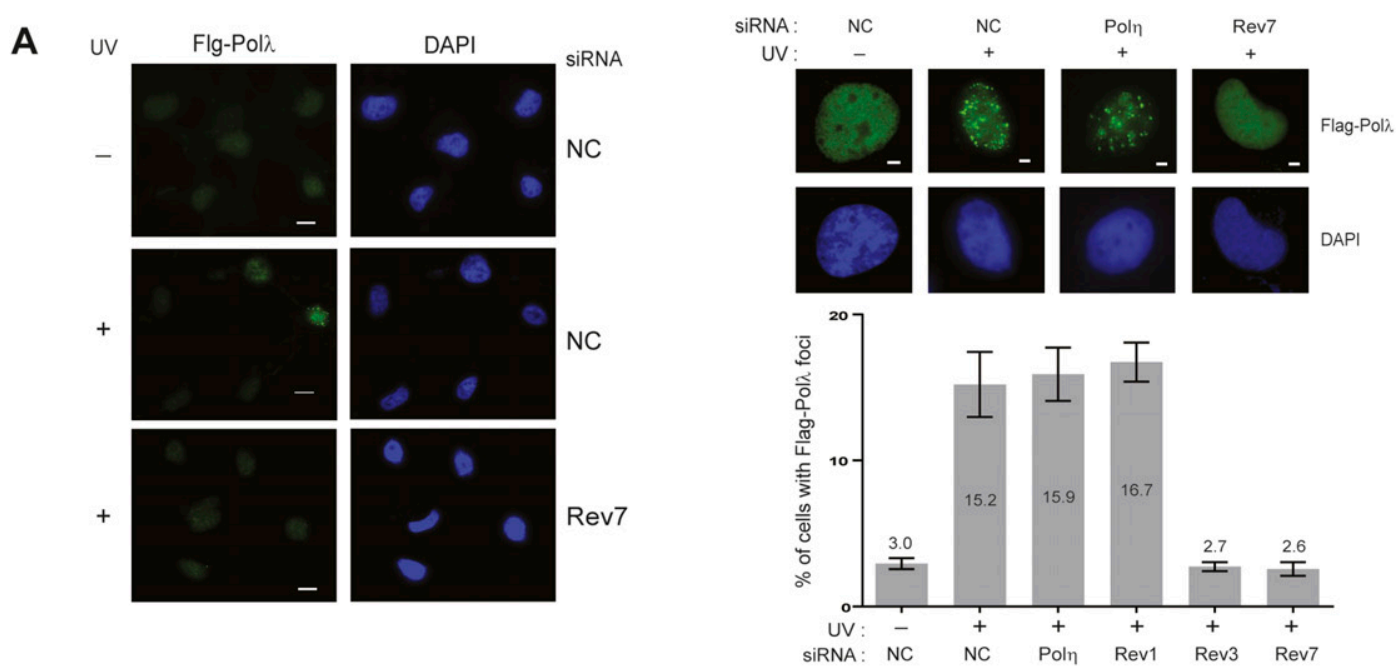

B
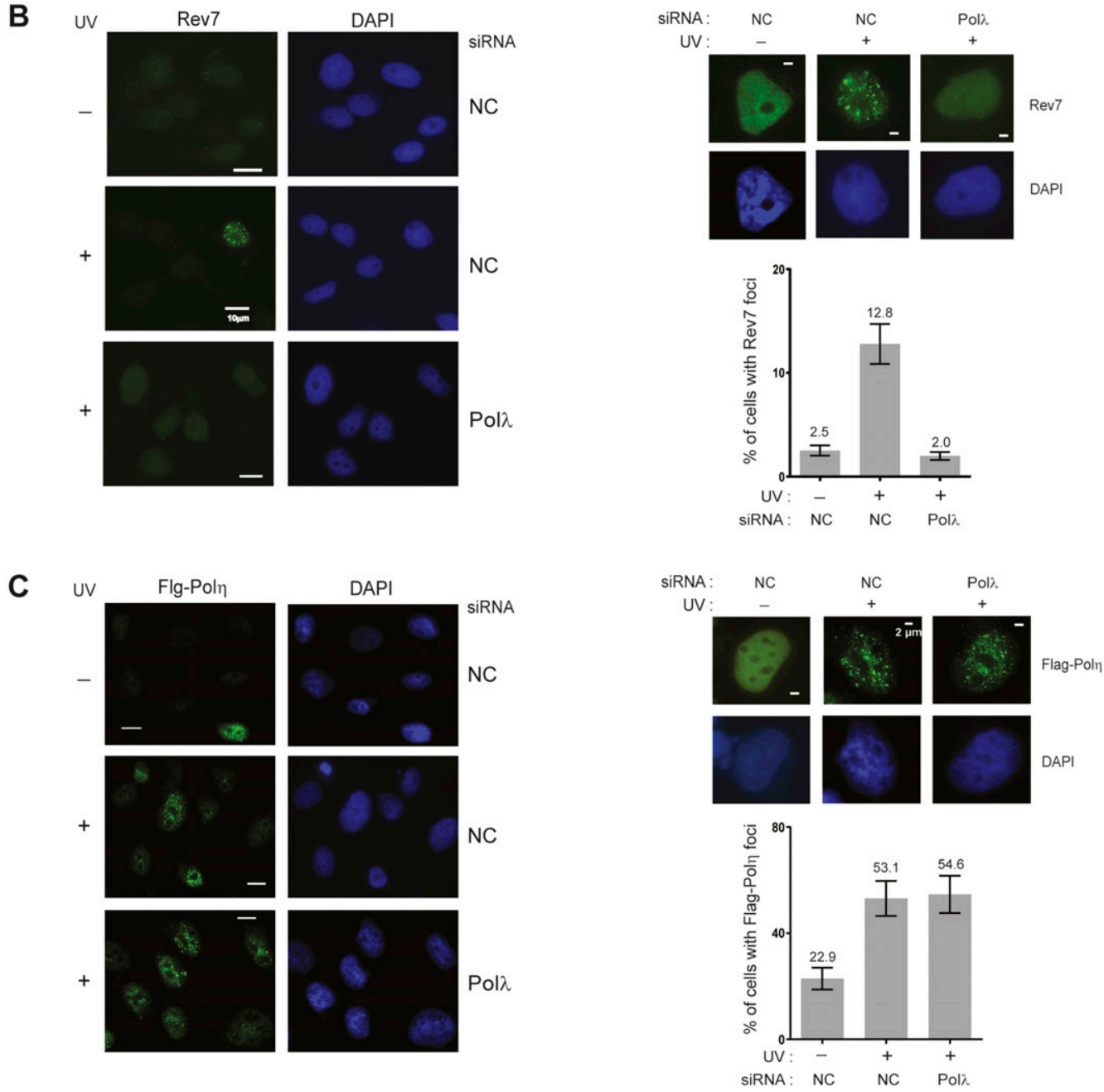

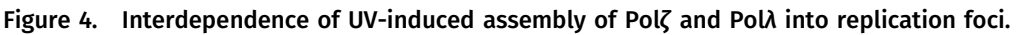

(A) Requirement of Rev3 or Rev7 for UV-induced assembly of Pol $\lambda$ into replication foci. GM637 HFs expressing Flag-Pol $\lambda$ were treated with siRNAs. After $48 \mathrm{~h}$ of siRNA treatment, cells

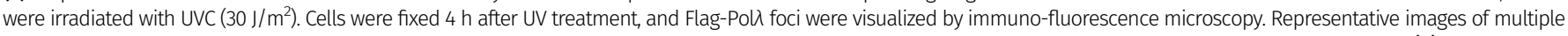
cells are shown on the left and magnified single cell images of Flag-Poll foci are shown on the right on top; quantification of cells containing these foci is shown below. (B) Requirement of Pol $\lambda$ for UV-induced assembly of Rev7 into replication foci. GM637 HFs were treated with siRNAs. Rev7 foci in multiple cells are shown on the left and magnified single cell images of Rev7 foci and quantification analysis are shown on the right. (C) Pol $\lambda$ does not affect UV-induced assembly of Pol $\eta$ into replication foci. XPV HFs expressing Flag-Pol $\eta$ were treated with siRNAs. Flag-Poln foci in multiple cells are shown on the left and magnified single cell images of Flag-Poln foci and quantification analysis are shown on the right. $60 \times$ magnification was used for images. For each analysis, $\sim 500$ cells were analyzed from three independent experiments. Scale bar for foci on the left is $10 \mu \mathrm{m}$ and for foci on the right is $2 \mu \mathrm{m}$. 
chromatin fractions from UV-irradiated HFs, both the Pold and ReV7 proteins co-IP with ub-PCNA, confirming that this protein assembly occurs in conjunction with ub-PCNA (Fig 5C)-a prerequisite for DNA damageinduced assembly of TLS Pols in human cells (Yoon et al, 2019b, 2015).

\section{Pol $\lambda$ 's BRCT domain is not required for TLS through a (6-4) photoproduct in human cells}

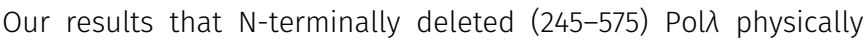

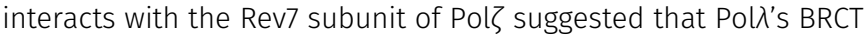
domain may not be required for its role in TLS in human cells. Because Pol $\lambda$ 's DNA synthesis activity is required for TLS through (6-4) PPs in human cells and because TLS through the (6-4) PPS would require the sequential roles of $\mathrm{Pol} \lambda$ and $\mathrm{Pol} \zeta$ in nt insertion opposite the (6-4) PP and in the subsequent extension of synthesis, respectively, we examined the effects of $\mathrm{N}$-terminally deleted Pol $\lambda$ on TLS opposite (6-4) TT PP in human cells. As shown in Table 6, in WT HFs depleted for Pol $\lambda$ and harboring the vector plasmid, TLS occurs with a frequency of $\sim 13 \%$, whereas expression of WT Pol $\lambda$ raises TLS frequency to $\sim 27 \%$ and expression of catalytically inactive Pol$\lambda$ reduces TLS frequency to the same level as in the vector control-consistent with the requirement of

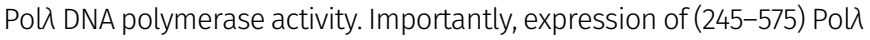
(Fig S1C) restores TLS frequency to WT levels (Table 6), indicating that the lack of the N-terminal domain, which includes the BRCT domain and the proline-rich region, has no untoward effect on the capacity of Pol $\lambda$ to carry out its role in DNA synthesis opposite (6-4) PPs as well as

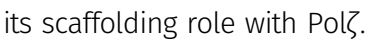

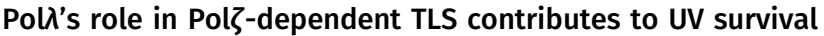

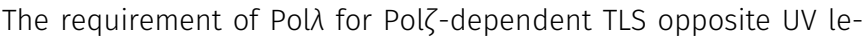
sions and for Pol $\zeta$ localization into foci predicted that the two Pols would contribute to UV survival to the same extent. Accordingly, we find that depletion of either Pol $\lambda$, Rev3, or Rev7 confers the same level of reduction in UV survival in $\mathrm{HFs}$ (Fig 6A). As expected from the involvement of Pol $\lambda$ and $\mathrm{Pol} \zeta$ in the same TLS pathway, UV sensitivity remains the same in cells co-depleted for Pol $\lambda$ and Rev 3 as in cells depleted for Pol $\lambda$ or Rev3 alone (Fig 6A). Depletion of Pol $\theta$ or Poln results in a greater reduction in UV survival, concordant with their relatively more significant contribution to TLS opposite UV lesions (Fig $6 \mathrm{~A})$. And consistent with the role of Pol$\lambda / \mathrm{Pol} \zeta$ as an alternate to Polndependent TLS through CPDs and (6-4) photoproducts, depletion of Polג, Rev3, or Rev7 reduced UV survival of XPV HFs to nearly the same extent (Fig 6B). In Pol $\lambda^{-/-}$MEFs, we confirmed that Rev3 depletion caused no further reduction in UV survival whereas depletion of Poln or Pol $\theta$ reduced UV survival (Fig 6C), and as expected from their relative contribution to TLS, Poln depletion conferred a greater reduction in UV survival than Pol $\theta$ depletion (Fig 6C).

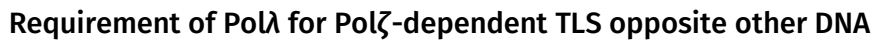 lesions}

To establish that Pol $\lambda$ 's role in TLS as an indispensable component of Pol $\zeta$ extends to other DNA lesions, we analyzed its role in TLS opposite thymine glycol $(\mathrm{Tg})$ and $1, \mathrm{~N}^{6}$-ethenodeoxyadenine $(\varepsilon \mathrm{dA})$. $\mathrm{Tg}$ is generated from the reaction of thymine with hydroxyl radicals resulting from aerobic respiration and from exposure to chemical oxidants or ionizing radiation. $\varepsilon \mathrm{dA}$ is formed in DNA through interaction with aldehydes derived from lipid peroxidation, a normal chain reaction process that initiates from the oxidation of polyunsaturated fatty acids in cell membranes and results in the formation of a variety of highly reactive aldehydes.

We have shown previously that replication through the Tg adduct is conducted via two alternate TLS pathways dependent upon either Polk/Pol or Pol $\theta$ (Yoon et al, 2010a, 2014) (see also Fig 7A). In the Polk/Polろ pathway, following nt insertion by Polk opposite the Tg adduct, Pol $\zeta$ would extend synthesis from the nt opposite $T g$, and this pathway promotes error-free TLS through the lesion. In the
A

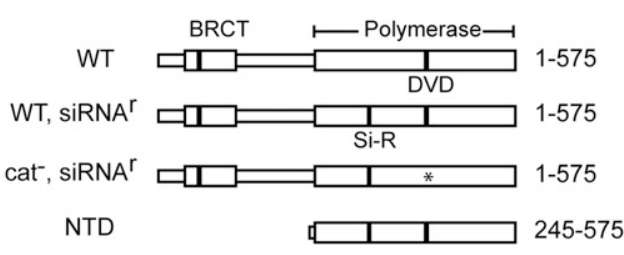

C

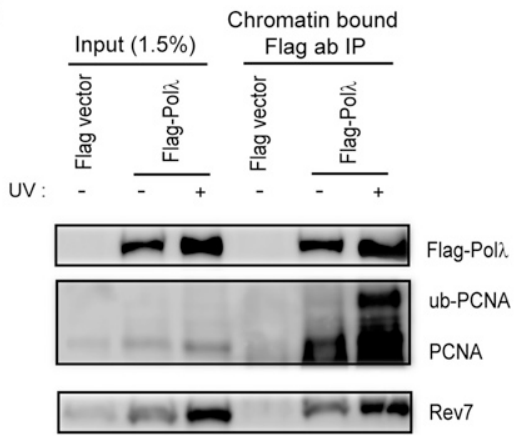

B
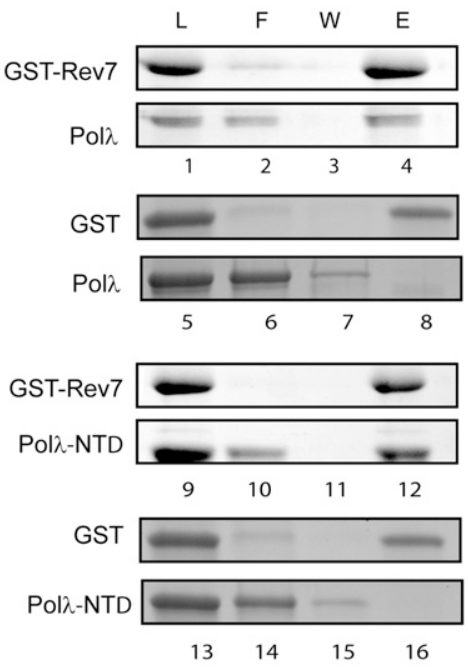

Figure 5. Physical interaction of Poli with Rev7. (A) Schematic representation of the Pold protein. Linear boxes represent the amino acid primary structure of Pol $\lambda$ and protein residues are given on the right. The BRCT and polymerase subdomains are labeled and indicated by larger boxes. The position of the catalytic residues Asp427 and Asp 429 are indicted by DVD, and the asterisk indicates that the catalytic residues were mutated to alanines. The position of the silent siRNA resistant mutant sequence is indicted by Si-R. Genotypes are given on the left. (B) Physical interaction of Pol $\lambda$ with Rev7. Purified GST-tagged Rev7 or GST protein alone was incubated with WT Pol $\lambda$ or $\mathrm{N}$-terminally deleted Pol $\lambda$-NTD and GST affinity pull down assays were performed as described in the Materials and Methods section. Protein aliquots from the load (L), flow through (F), wash (W), and elution (E) steps were resolved by $12 \%$ SDS-PAGE gel and proteins were visualized by Coomassie blue R-250 staining. Protein identities are given on the left. (C) Co-immunoprecipitation (co-IP) of Flag-Pol $\lambda$ with Rev7 in chromatin fractions. GM637 cells expressing Flag-Pol $\lambda$ were UV irradiated and incubated for $4 \mathrm{~h}$. Chromatin extracts were prepared and immunoprecipitated with Flag M2-agarose. Co-IP of Flag-Pol $\lambda$ with ub-PCNA and Rev7 was determined by Western blot analysis. 
Table 6. Effects of WT (1-575), catalytically inactive D427A, D429A, or N-terminally deleted (245-575) Poli on TLS opposite a (6-4) TT photoproduct carried on the leading strand in WT HFs.

\begin{tabular}{|c|c|c|c|c|}
\hline DNA lesion & Vector expressing & Number of $\mathrm{Kan}^{+}$colonies & Number of blue colonies among Kan ${ }^{+}$ & $\operatorname{TLS}(\%)^{\mathrm{a}}$ \\
\hline \multirow{4}{*}{$(6-4) \pi \mathrm{PP}$} & Vector control & 346 & 45 & 13.0 \\
\hline & WT (1-575) Pold & 438 & 119 & 27.2 \\
\hline & D427A, D429A Pol入 & 418 & 53 & 12.7 \\
\hline & (245-575) Pold & 396 & 101 & 25.5 \\
\hline
\end{tabular}

${ }^{\text {a }}$ Statistical analyses of these data are shown in Table 54.

alternative pathway, Pol $\theta$ performs both steps of TLS and it acts in an error-prone manner (Yoon et al, 2010a, 2014). As shown in Table 7, TLS opposite Tg occurs at a frequency of $23 \%$ in WT MEFs. In Pol $\lambda^{-1-}$ MEFs, TLS is reduced to $~ 10 \%$ and a similar reduction in TLS frequency occurs upon depletion of either Polk or Rev3, consistent

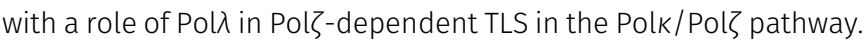
In Pol $\lambda^{-1-}$ MEFs depleted for Pol $\theta$, or in Pol $\theta^{-/-}$MEFs depleted for Pol $\lambda$, where both the Polk/Pol $\zeta$ and Pol $\theta$ pathways would be rendered inactive, TLS is almost completely abrogated, as only a very low residual level of TLS ( $1 \%)$ remains. From these data, we

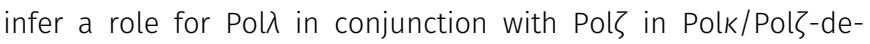
pendent TLS pathway opposite Tg (Fig 7A).

TLS opposite $\varepsilon d A$ is performed by a major Polı/Polל-dependent pathway in which after nt insertion opposite $\varepsilon d A$ by Polı, Pol $\zeta$ would extend synthesis, and this pathway operates in an error-free manner (Yoon et al, 2019a) (see also Fig 7B). In the Polı/Polל pathway, Rev1 performs a non-catalytic role as a scaffolding component of Polı. In another relatively minor pathway, Rev1 functions in TLS opposite $\varepsilon \mathrm{dA}$ as a DNA polymerase and acts in an error-prone manner. Pol $\theta$ promotes TLS through $\varepsilon d A$ via a third pathway and it also operates in an error-prone manner (Yoon et al, 2019a). As shown in Table 7, TLS opposite $\varepsilon d A$ occurs at a frequency of $\sim 22 \%$ in WT MEFs. TLS frequency is reduced to $\sim 10 \%$ in Pol$\lambda^{-/-}$ MEFs and TLS frequency remains the same in Pol$\lambda^{-/-}$MEFs depleted for Polı or Rev3 (Table 7), consistent with the requirement of Pol $\lambda$ for

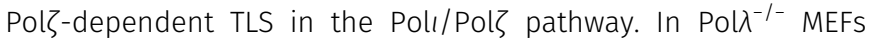
depleted for Pol $\theta$ or in Pol $\theta^{-/-}$MEFs depleted for Pol $\lambda$ or Rev3 (Table 7), only residual TLS ( $\sim \%)$ remains; it reflects the minor contribution of Rev1 polymerase-dependent TLS that operates in the absence of the Polı/Pol $\zeta$ and Pol $\theta$ pathways (Yoon et al, 2019a). These data in Pol$\lambda^{-/-}$

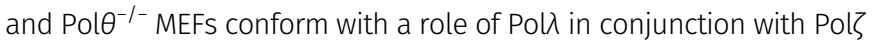
in Polı/Polろ-dependent TLS opposite $\varepsilon d A$ (Fig 7B).

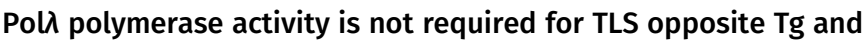
$\varepsilon \mathrm{dA}$ adducts

Our proposal that after nt insertion by Polk opposite the Tg lesion, Pol $\zeta$ would extend synthesis (Yoon et al, 2010a) predicted that only the non-catalytic scaffolding role of Pol $\lambda$ would be required for Pol -dependent TLS opposite Tg. Similarly, the role of Polı in inserting a nt opposite $\varepsilon \mathrm{dA}$ and of $\mathrm{Pol} \zeta$ in extending subsequent synthesis (Nair et al, 2006; Yoon et al, 2019a) predicted that only the

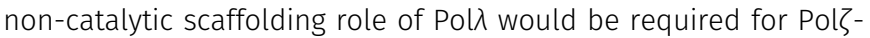
dependent TLS opposite $\varepsilon d A$. To verify these predictions, we expressed WT Poll and DNA polymerase-defective D427A, D429A mutant Pol $\lambda$ in Pol$\lambda^{-1-}$ MEFs and analyzed the frequency of TLS opposite the $\mathrm{Tg}$ or $\varepsilon \mathrm{dA}$ lesion carried on the duplex plasmid in these MEFs. In Pol $\lambda^{-1-}$ MEFs, TLS opposite Tg occurs with a frequency of $10 \%$ (Table 3). Our results that TLS frequency in $\mathrm{Pol}^{-1-}$ MEFs expressing WT Pol $\lambda$ rises to $\sim 21 \%$ and that TLS frequency in Pol$\lambda^{-1-}$ MEFs expressing catalytically inactive mutant Pol $\lambda$ remains the same as in Pol$\lambda^{-/-}$MEFs expressing WT Pol $\lambda$ confirm that only the non-catalytic scaffolding role of Pol $\lambda$ is required for TLS opposite Tg (Table 3 and Fig 7A). And the observation that catalytically inactive Pol $\lambda$ supports WT levels of TLS opposite $\varepsilon d A$ indicates that only the non-catalytic scaffolding role of Pol $\lambda$ is required for TLS opposite this DNA lesion (Table 3 and Fig 7B).

\section{Requirement of Polろ DNA polymerase activity for TLS through (6-4) TT photoproduct}

The biochemical evidence that purified Pol $\lambda$ can insert a nt opposite both the 3'T and 5'T of the (6-4) TT PP (Fig 2B) raised the possibility

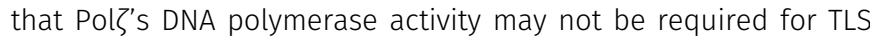
through this DNA lesion. To examine this, we expressed full-length WT Rev3 and mutant Rev3 in which the active site residues D2781 and D2783 have both been changed to alanines. In HFs depleted for Rev3 and expressing no Rev3 (vector control), TLS opposite (6-4) TT PP occurs at a frequency of $14 \%$. TLS frequency rises to $27 \%$ in cells expressing WT Rev3, whereas in cells expressing the D2781A and D2783A Rev3 mutant, TLS frequency is reduced to the same level as in cells harboring the vector control (Table 8). Thus, Rev3 DNA polymerase activity is required for TLS through (6-4) TT PP.

\section{Discussion}

\section{Polג promotes replication through DNA lesions in conjunction with Pol了}

Genetic and biochemical studies have established an indispensable role of Rev1 as a scaffolding component of Pol $\zeta$ in yeast and Rev1/Pol $\zeta$-dependent TLS operates in a highly error-prone manner (Baynton et al, 1999; Nelson et al, 2000; Haracska et al, 2001; Gibbs et al, 2005; Acharya et al, 2006). Moreover, Rev1 functions together with Pol $\zeta$ in TLS that occurs during gap filling reactions in human or mouse cells (Yoon et al, 2015) and the dependence of cancer cells upon Rev1/Pol $\zeta$ for DNA damage induced mutagenesis (Doles et al, 2010; Xie et al, 2010) suggests that during malignant transformation, cancer cells acquire the potential of highly elevated mutability, afforded by Rev1/Polろ. In striking contrast, TLS analyses with a 
A

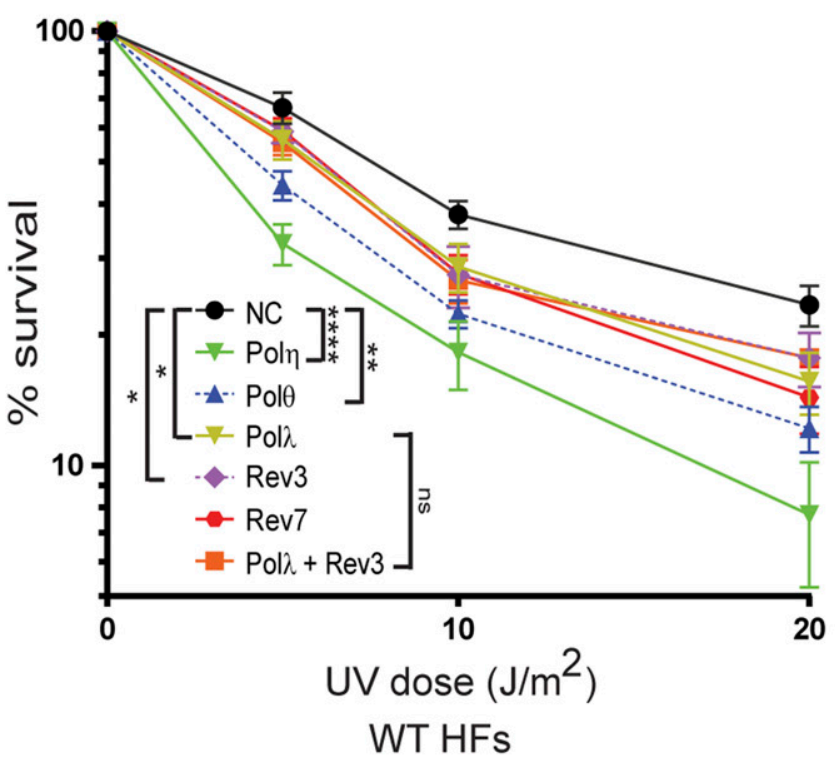

B

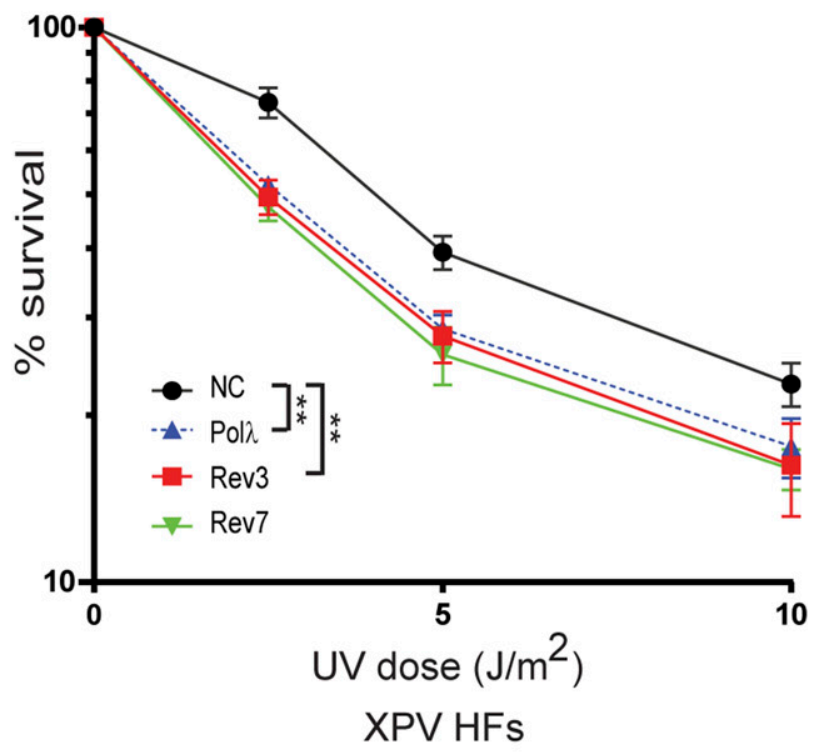

\section{C}

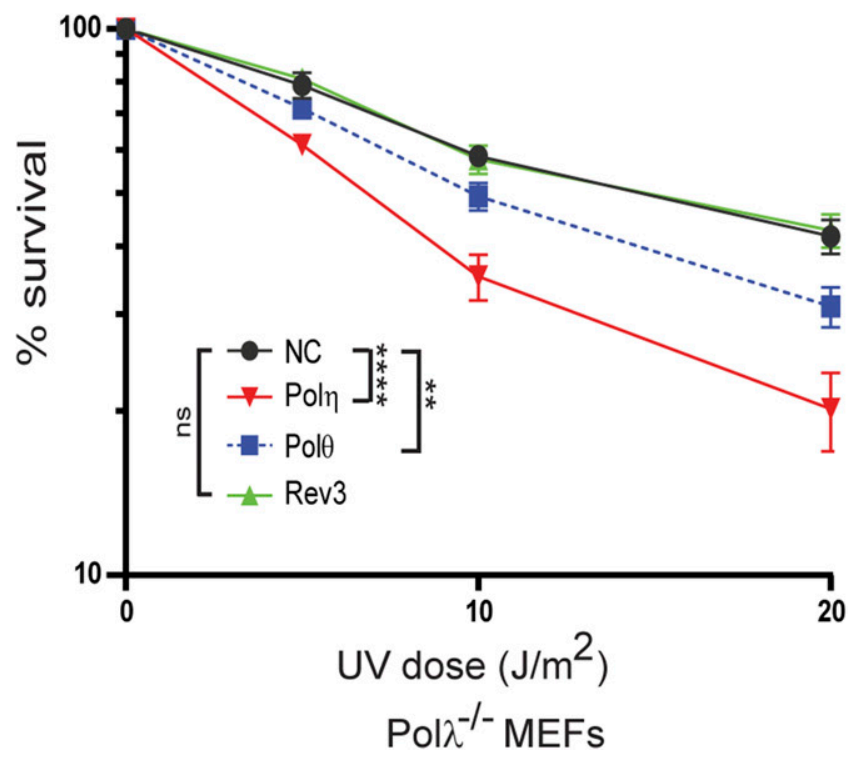

Figure 6. UV survival assays.

GM637 HFs, XPV (XP30R0) HFs, or Pol$\lambda^{-/-}$MEFs were treated with siRNAs for $48 \mathrm{~h}$ and irradiated with UV light in PBS buffer. Cells were incubated for additional $48 \mathrm{~h}$ after UV irradiation and UV survival was determined by the MTS assay. The data represent the mean and SD of results of four independent experiments. Student's two-tailed $t$

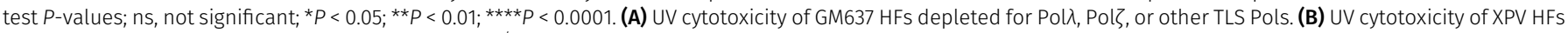

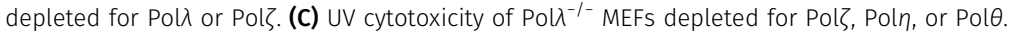

variety of DNA lesions present on the template for leading or lagging strand replication of a duplex plasmid carried in normal human cells (not derived from cancers) have shown that Rev1 functions together with $Y$-family Pols $\eta$, 1 , or $k$ and not with $\zeta$ (Yoon et al, 2019a, 2018, 2017, 2015). Importantly, the TLS mechanisms inferred from the duplex plasmid system reflect the mechanisms that operate during cellular replication in normal cells. For example, the reduction in the rate of RF progression through UV lesions in
Pol $\eta^{-1-}$, Pol $\theta^{-1-}$, and Pol $\eta^{-1-}$ Pol $\theta^{-1-}$ primary MEFs conforms with the roles deduced for these Pols from TLS analyses opposite UV lesions in the plasmid system (Yoon et al, 2019b). Altogether, the evidence indicates that the TLS mechanisms that operate during replication in normal human cells differ from the mechanisms inferred from gap repair assays or from studies in cancer cells.

The requirement of Rev1 for TLS mediated by Y-family Pols and not for Polろ-dependent TLS suggested that some other protein 
A

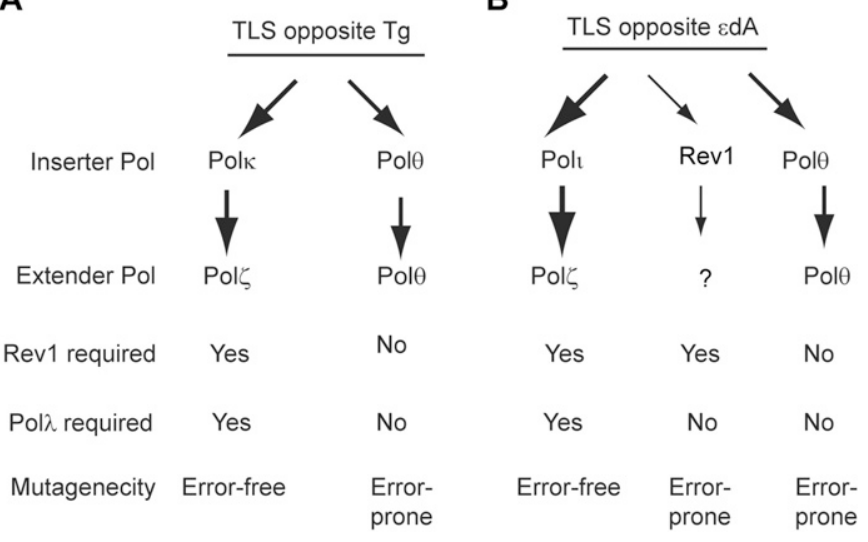

PolO. (3) From analyses of UV-induced mutations opposite CPDS and (6-4) PPs analyzed in the cll gene in BBMEFs, we established that Pol $\lambda$ affects mutation frequencies and mutational spectra similar to

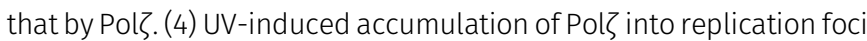

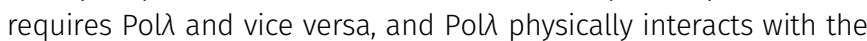

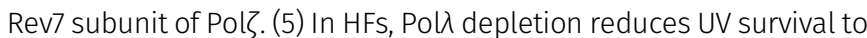
the same extent as occurs upon Pol $\zeta$ depletion, and co-depletion of

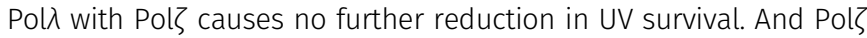
depletion causes no further reduction in UV survival in Pol$\lambda^{-/-}$MEFs. (6) Opposite DNA lesions that include Tg and $\varepsilon d A$ adducts, Pol $\lambda$ functions together with $\mathrm{Pol} \zeta$ in error-free TLS pathways.

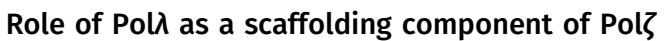

Our evidence that Pol $\lambda$ 's DNA polymerase activity is not required for TLS opposite CPDs, Tg, or $\varepsilon \mathrm{dA}$ indicates that only the scaffolding role of

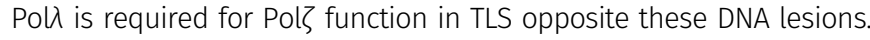
The lack of requirement of Pol $\lambda$ polymerase activity for TLS opposite these DNA lesions is compatible with the roles that have been deduced from biochemical and structural studies and assigned to other Pols. The requirement of Pol入 DNA polymerase activity for TLS opposite (6-4) $\Pi \mathrm{PPs}$ in human cells and the ability of purified Pol $\lambda$ to insert a nt opposite the 3'T and 5'T of the (6-4) TT PP supports a role for Pol $\lambda$ in nt insertion opposite the photoproduct from which Pol $\zeta$ would extend synthesis. Thus, in addition to its indispensable non-catalytic role with

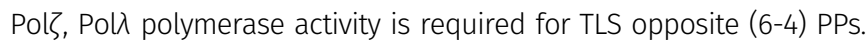

\section{Nucleotide insertion opposite (6-4) photoproduct by Polג}

The evidence that purified Pold inserts an A opposite both the $3^{\prime} T$ and 5'T residue of (6-4) TT conforms with the genetic evidence that Pol $\lambda /$ Pol $\zeta$-dependent TLS operates in an error-free manner in

Table 7. The effects of siRNA knockdowns of TLS Pols on replicative bypass of a thymine glycol or a 1 , $\mathbf{N}^{6}$-ethenodeoxyadenosine carried on the leading strand template in wild type, Pol$\lambda^{-1-}$, or Pol $\theta^{-I-}$ MEFs.

\begin{tabular}{|c|c|c|c|c|c|}
\hline DNA lesion & MEFs & SiRNA & Number of $\mathrm{Kan}^{+}$colonies & Number of blue colonies among $\mathrm{Kan}^{+}$colonies & TLS (\%) ${ }^{\mathrm{a}}$ \\
\hline \multirow{7}{*}{$\operatorname{Tg}$} & WT & NC & 317 & 73 & 23.0 \\
\hline & \multirow{4}{*}{ Poll $\lambda^{-/-}$} & NC & 405 & 42 & 10.4 \\
\hline & & Polk & 381 & 41 & 10.8 \\
\hline & & Rev3 & 423 & 48 & 11.3 \\
\hline & & Pol $\theta$ & 462 & 6 & 1.3 \\
\hline & \multirow{2}{*}{ Pol $\theta^{-/-}$} & NC & 360 & 42 & 11.7 \\
\hline & & Pold & 428 & 6 & 1.4 \\
\hline \multirow{8}{*}{$\varepsilon \mathrm{dA}$} & WT & NC & 322 & 70 & 21.7 \\
\hline & \multirow{4}{*}{ Poll $\lambda^{-1-}$} & NC & 304 & 32 & 10.5 \\
\hline & & Polı & 337 & 38 & 11.3 \\
\hline & & Rev3 & 388 & 42 & 10.8 \\
\hline & & Pol $\theta$ & 334 & 11 & 3.3 \\
\hline & \multirow{3}{*}{ Pol $\theta^{-1-}$} & NC & 341 & 36 & 10.6 \\
\hline & & Pold & 401 & 13 & 3.2 \\
\hline & & Rev3 & 312 & 12 & 3.8 \\
\hline
\end{tabular}

aStatistical analyses of these data are shown in Table S5. 
Table 8. Effects of catalytically inactive D2781A and D2783A Rev3 on TLS opposite a (6-4) TT photoproduct carried on the leading strand in WT HFs.

\begin{tabular}{|c|c|c|c|c|}
\hline DNA lesion & Vector expressing & Number of $\mathrm{Kan}^{+}$colonies & Number of blue colonies among $\mathrm{Kan}^{+}$ & $\operatorname{TLS}(\%)^{\mathrm{a}}$ \\
\hline \multirow{3}{*}{$(6-4) \pi T P P$} & Vector control & 408 & 58 & 14.2 \\
\hline & WT (1-3130) Rev3 & 318 & 86 & 27.0 \\
\hline & D2781A and D2783A Rev3 & 341 & 47 & 13.8 \\
\hline
\end{tabular}

${ }^{a}$ Statistical analyses of these data are shown in Table S6.

human cells. A (6-4) TT PP induces a large structural distortion in DNA in which it confers a $44^{\circ}$ bend in the DNA helix and the $3^{\prime} \mathrm{T}$ is oriented perpendicular to the 5'T (Kemmink et al, 1987; Kim \& Choi, 1995; Kim et al, 1995; Lee et al, 1999), impairing the ability of the 3'T to form a normal $\mathrm{W}-\mathrm{C}$ pair with the correct nt. Since Pold normally uses $\mathrm{W}-\mathrm{C}$ base pairing for DNA synthesis, Pold may not accommodate a (6-4) PP in its active site such that the $3^{\prime}$ pyrimidine residue of the photoproduct forms a $\mathrm{W}-\mathrm{C}$ base pair with the correct incoming $\mathrm{nt}$. That raises the possibility that purified Pol $\lambda$ inserts an A opposite both pyrimidines of the photoproduct, wherein the lesion adopts an extrahelical configuration resembling an abasic lesion.

Regardless of whether purified Pol $\lambda$ performs error-free nt incorporation opposite (6-4) TT photoproduct by $\mathrm{W}$-C base pairing or

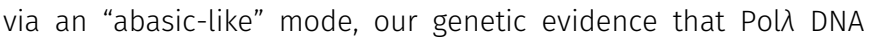
polymerase activity is required for TLS opposite (6-4) PPs (Table 3) and that Pol $\lambda$ conducts error-free TLS opposite (6-4) PPs formed at $\mathrm{CC}$, TC, or TT sequences in the $\mathrm{Cll}$ gene integrated into the genome (Table 5 and Fig 3B) implies that in human and mouse cells, Pol $\lambda$ incorporates a correct nt opposite the (6-4) photoproducts formed at dipyrimidine sequences from which Polろ extends synthesis.

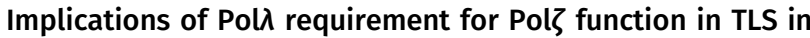 human cells}

Our TLS analyses have indicated that, overall, Pol $\lambda /$ Pol $\zeta$-dependent TLS operates in an error-free fashion in human cells. Thus, of the four DNA lesions examined here, Pol $\lambda / \mathrm{Pol} \zeta$ contributes to error-free TLS opposite (6-4) PPs, Tg, and $\varepsilon \mathrm{dA}$, whereas it functions in an errorprone TLS pathway opposite CPDs. The ability of Pol $\lambda /$ Pol $\zeta$ to perform error-free TLS through (6-4) PPs stands in stark contrast to the role of Rev1/Pol $\zeta$ in error-prone TLS opposite (6-4) PPs in yeast cells (Gibbs et $\mathrm{al}, 2005$ ) and the role of Rev1/Pol $\mathrm{C}$ in error-prone TLS opposite (64) TT PP that occurs during gap filling reaction in human or mouse cells (Yoon et al, 2015). The requirement of Pol $\lambda / P o l \zeta$ for error-free TLS through the Tg and $\varepsilon d A$ lesions further suggests that after the insertion of a nt by Polk opposite Tg, or the insertion of a nt by Polı

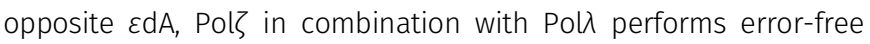
synthesis during the extension phase of TLS. In the Pol $\lambda /$ Pol $\zeta$ ensemble, Pol $\zeta$ may be inhibited from extending synthesis from the wrong nts inserted opposite DNA lesions by the other Pols, promoting thereby a more error-free mode of TLS. In this regard, Pol $\lambda$ 's effect on TLS by Pol $\zeta$ would be diametrically opposite to the enhancement in the proficiency of extension of synthesis from the wrong nts that occurs in TLS mediated by Rev1/Polろ (Acharya et al, 2006).

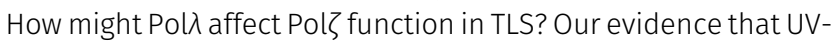

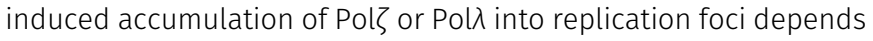
upon each other suggests that the assembly of Pol $\lambda$ together with

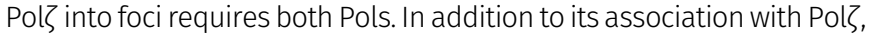

Pol $\lambda$ may promote the assembly of additional proteins which serve to increase the fidelity and efficiency of the Pol $\lambda /$ Pol $\zeta$ ensemble in TLS. In the Pol $\lambda / P o l \zeta$ multi-protein ensemble, Pol $\lambda$ may acquire the ability to form W-C base pair with the correct nt opposite the (6-4) PPs formed at the $\Pi, \mathrm{TC}$, or $\mathrm{CC}$ dipyrimidine sites. In thymine glycol, because of the addition of hydroxyl groups at C5 and C6, the C5 methyl group protrudes in the axial direction and that prevents the base $5^{\prime}$ to $\mathrm{Tg}$ from stacking above it. Hence, the insertion of a correct nt opposite this extra-helical base would require $\mathrm{Pol} \zeta$ to accommodate this base in its active site such that it engages in $\mathrm{W}$-C pairing with the correct $\mathrm{nt}$. In the multi-protein ensemble of Pol $\zeta$ with Pol $\lambda$ and other proteins, the extrahelical base may be pushed into a normal helical configuration in the Pol $\zeta$ active site enabling Pol $\zeta$ to carry out nt insertion opposite the base $5^{\prime}$ to $\mathrm{Tg}$ with a high fidelity. Similarly, any structural distortions in the DNA helix imposed by the $\varepsilon \mathrm{dA}$ lesion at the extension step of TLS could be minimized in the Pol $\zeta$ active site in the Pol $\lambda / \mathrm{Pol} \zeta$ ensemble. Altogether, the adoption of Pol $\lambda$ as an integral component of Pol $\zeta$ may have evolved to provide human cells a strategy for imposing a predominantly error-free mode of TLS upon Polろ.

\section{Conclusions}

Our evidence that Pold functions as an indispensable scaffolding component of Pol $\zeta$ for TLS that occurs during replication in normal human cells depicts an entirely new and unexpected role for Pol $\lambda$.

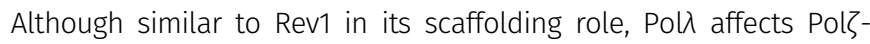
dependent TLS differently than Rev1. Thus, unlike the role of Rev1/

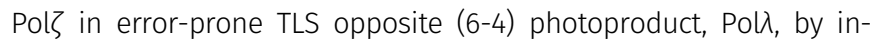
corporating a correct nt opposite the photoproduct by $\mathrm{W}-\mathrm{C}$ base pairing, would enable Pol$\lambda / P o l \zeta$-dependent TLS to operate in an error-free manner in human cells. This role of Pol $\lambda$ in TLS opposite (64) photoproduct strongly suggests that opposite many other such distorting DNA lesions, Pol $\lambda$ would similarly insert a correct nt from which Pol $\zeta$ would extend synthesis. Similar to the role of Pol $\lambda / \mathrm{Pol} \zeta$ in error-free TLS opposite the Tg and $\varepsilon d A$ lesion, complex formation with

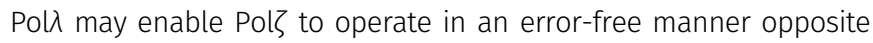
other DNA lesions where only its scaffolding role is required.

\section{Materials and Methods}

\section{Expression and purification of Poli}

The cDNA's encoding the WT Pol (residues 1-575) or the N-terminally

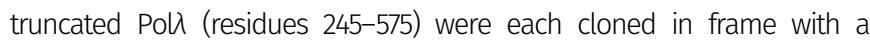
PreScission Protease cleavable GST tag in pBJ842 (Johnson et al, 2006) generating plasmids pB/2043 and pB/1431, respectively. Plasmids were transformed into yeast strain YRP654 and protein expression was induced 
by the addition of $2 \%$ galactose. Proteins were purified using a standard GST purification protocol (Johnson et al, 2006). Briefly, frozen yeast cells were resuspended in cell breakage buffer (50 mM Tris-HCl, pH 7.5, 20\% sucrose, $500 \mathrm{mM} \mathrm{NaCl}, 1 \mathrm{mM}$ EDTA, 10 mM $\beta$-mercaptoethanol, 1 mM benzamidine $\mathrm{HCl}$, and complete-EDTA-free protease inhibitors [Roche]) and disrupted on a French press. Clarified protein extract was treated with $0.208 \mathrm{~g} / \mathrm{ml} \mathrm{am}$ monium sulfate, and precipitated proteins were resuspended and dialyzed overnight in glutathione binding buffer (GBB, 50 mM Tris-HCl, pH 7.5, 10\% glycerol, $500 \mathrm{mM} \mathrm{NaCl}, 1 \mathrm{mM}$ benzamidine $\mathrm{HCl}$, and Roche complete protease inhibitors). Proteins were incubated with glutathione sepharose for several hours before washing with GBB containing $1 \mathrm{M} \mathrm{NaCl}$. Sepahrose was then equilibrated in GBB containing $150 \mathrm{mM} \mathrm{NaCl}$ without Pl's, and proteins were eluted by treatment with PreScission Protease (GE Healthcare) overnight at $4^{\circ} \mathrm{C}$. Proteins were harvested and residual Prescission Protease was removed by incubation with fresh Glutathione Sepharose. Proteins were concentrated and aliquots frozen at $-70^{\circ} \mathrm{C}$.

\section{DNA polymerase assays}

The standard DNA polymerase reaction $(5 \mu \mathrm{l})$ contained $25 \mathrm{mM}$ Tris- $\mathrm{HCl}$ (pH 7.5), 5 mM MgCl 2,1 mM DTT, 10\% glycerol, $100 \mu \mathrm{g} / \mathrm{ml} \mathrm{BSA}$, and $5 \mathrm{nM}$ DNA substrate. Reactions contained $100 \mu \mathrm{M}$ of either a single deoxynucleotide triphosphate (dGTP, dATP, dTTP, or dCTP) or 100 $\mu \mathrm{M}$ each of all four. The DNA substrate was generated by annealing a $5^{\prime}$ ${ }^{32} \mathrm{P}$ labeled oligonucleotide primer to a 75-nucleotide oligonucleotide template of the sequence $5^{\prime}$-AGCAAGTCAC CAATGTCTAA GAGT CGTATIATGC CTACACTGGA GTACCGGAGC TACGTCGTGA CTGGGAAAAC-3', which was either unmodified or contained a (6-4) $\Pi$ photoproduct or a cis-syn $\pi$ dimer (CPD) at the underlined position. The cis-syn $\pi$ dimer and the (6-4) $\Pi$ photoproducts were introduced into the 10mer 5'-CGTATTATGC$3^{\prime}$ by UV treatment, and following HPLC purification, ligated to flanking 25-mer and 40-mer oligonucleotides as described (Johnson et al, 2001) to generate the 75-mer. For standing start reactions, the 44 nucleotide primer 5'-GTITCCCAG TCACGACGAT GCTCCGGTAC TCCAGTGTAG GCAT-3' was annealed to the template, and for running start reactions, the 40mer 5'-GTITCCCAG TCACGACGAT GCTCCGGTACTCCAGTGTAG-3' was used. All oligonucleotides were PAGE-purified. Reactions contained 5 nM DNA polymerase $\lambda$ and were carried out at $37^{\circ} \mathrm{C}$ for $20 \mathrm{~min}$. The reactions were stopped by addition of $30 \mu \mathrm{l}$ of loading buffer (95\% formamide, $20 \mathrm{mM}$ EDTA, $0.3 \%$ bromophenol blue, and $0.3 \%$ xylene cyanol), and the reaction products were resolved on a 10\% TBE-polyacrylamide gel containing 8M urea. Gels were dried and products were visualized by phoshorimaging on a Typhoon FLA 7000 (GE Healthcare Life Sciences).

\section{GST pull down experiments}

The physical interaction between GST-Rev7 and Pol $\lambda$ was carried out by using a protocol described before (Haracska et al, 2002) with minor modifications. Briefly, $\sim 2 \mu \mathrm{g}$ of either GST tagged Rev7 or GST protein each bound to $20 \mu \mathrm{L}$ glutathione sepharose beads was incubated with an equal

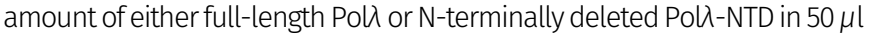
buffer I (50 mM Tris-HCl [pH 7.5], 150 mM NaCl, 5 mM dithiothreitol, 0.01\% Nonidet P-40, and $10 \%$ Glycerol). Protein-glutathione Sepharose mixtures were incubated at $25^{\circ} \mathrm{C}$ for $15 \mathrm{~min}$, followed by incubation at $4^{\circ} \mathrm{C}$ overnight with constant rocking. The beads were harvested by centrifugation at $1,000 \mathrm{~g}$ and the unbound protein flow through (F) fraction was collected. The beads were then washed three times each with 10 vol of buffer I. The bound proteins were then eluted with $20 \mu \mathrm{l}$ of $1 \times$ SDS-PAGE loading buffer. Aliquots of the protein mixture load (L), the flow through (F), the last washing fraction $(\mathrm{W})$, and the eluted protein fraction $(\mathrm{E})$ were resolved on a $12 \%$ denaturing polyacrylamide gel, followed by Coomassie Blue R-250 staining.

\section{Construction of plasmid vectors containing a cis-syn TT dimer or a (6-4) TT photoproduct}

The heteroduplex vectors containing a cis-syn TT dimer or a (6-4) TT photoproduct on the leading or lagging strand template were constructed as described previously (Yoon et al, 2009, 2010a).

\section{Cell lines and cell culture}

Normal human fibroblasts (Coriell Institute Cell Repository, GM00637), XPA-deficient fibroblasts (Coriell Institute Cell Repository, GM04429), XPV-deficient fibroblasts (Coriell Institute Cell Repository, GM03617), SV40-transformed Pol$\lambda^{-1-}$ MEFs, and big blue mouse embryonic fibroblasts (Agilent) were grown in DMEM medium (GenDEPOT) containing 10\% fetal bovine serum (GenDEPOT) and $1 \%$ antibiotic-antimycotic (GenDEPOT). Cells were grown on plastic culture dishes at $37^{\circ} \mathrm{C}$ in a humidified incubator with $5 \% \mathrm{CO}_{2}$

\section{Translesion synthesis assays in HFs and Pol$\lambda^{-1-}$ MEFs}

For siRNA knockdown of Pol$\lambda$, HPLC-purified duplex siRNA for human and mouse genes were purchased from Ambion. The siRNA sequences were human Pol$\lambda$ : 5'-GCUGGACCAUAUCAGUGAG-3'; mouse Pol $\lambda$ : 5'-GCACUACGAUGACUUCCUG-3'. The efficiency of Pol $\lambda$ knockdown was verified by Western blot analysis (Fig S1A). The siRNA knockdown efficiency of other TLS Pols as well as the detailed methods for TLS assay and for mutational analyses have been described previously (Yoon et al, 2015, 2010b, 2009).

\section{Western blot analysis}

$48 \mathrm{~h}$ after siRNA transfection, the cells were washed with PBS buffer and lysed with RIPA buffer ( $1 \times$ PBS, 1\% IP-40, 0.5\% sodium deoxycholate, and $0.1 \%$ SDS). After $1 \mathrm{~h}$ incubation on ice, the cellular mixture was centrifuged, and the supernatant was collected. Equivalent amounts $(\sim 30 \mu \mathrm{g})$ of prepared cellular extracts were separated on a 10\% SDS-polyacrylamide gel and transferred to a PVDF membrane (Bio-Rad). The membranes were probed with antibodies against human Pol入 (Bethyl Lab) or Flag (Sigma-Aldrich), followed by appropriate secondary antibodies conjugated with horseradish peroxidase. The signals were detected using ECL-Plus (GenDEPOT). For the loading control, anti- $\beta$-tubulin antibody (Santa Cruz Biotechnology) or antilamin B1 antibody (Abcam) was used.

\section{Stable expression of wild type and mutant Pold in HFs and Pol $\lambda^{-I-}$ MEFs}

SiRNA-resistant wild-type human Pol $\lambda$, or catalytic mutant (D427A D429A) Pol $\lambda$, or N-terminally deleted (245-575) Pol $\lambda$ cDNAs were cloned into the pCMV7-3xFlag-zeo vector (Sigma-Aldrich). The vectors were each transfected into SV40-transformed GM637 HFs or Pol $\lambda^{-/-}$MEFs 
by lipofectamine 2000 reagent (Invitrogen). After $24 \mathrm{~h}$ incubation, $0.5 \mu \mathrm{g}$ of zeocin (GenDEPOT) was added to the culture media. After an additional $3 \mathrm{~d}$ of incubation, the cells were washed with PBS buffer and were continuously cultured in media containing $250 \mathrm{ng}$ of zeocin for $\sim 2$ wk. Protein expression and siRNA knockdown efficiency were verified by Western blot analysis (Fig S1A-C).

\section{Stable expression of wild-type and mutant Rev3 in HFs}

siRNA-resistant wild-type human Rev3, or catalytic mutant (D2781A D2783A) Rev3 CDNAs were cloned into the pCMV7-3xFlag-zeo vector (Sigma-Aldrich). The vectors were each transfected into SV40 transformed GM637 HFs by lipofectamine 2000 reagent (Invitrogen). After $24 \mathrm{~h}$ incubation, $0.5 \mu \mathrm{g}$ of zeocin (GenDEPOT) was added to the culture media. After an additional $3 \mathrm{~d}$ of incubation, the cells were washed with PBS buffer and were continuously cultured in media containing $250 \mathrm{ng}$ of zeocin for $\sim 2$ wk. Protein expression was verified by Western blot analysis (Fig S1D).

\section{UV survival assays}

GM637 HFs, XPV (XP30R0) HFs, or Pol $\lambda^{-1-}$ MEFs were transfected with siRNAs and $48 \mathrm{~h}$ after siRNA transfection, the cells were treated with UV. For UV irradiation, the cells were washed with PBS buffer and irradiated with various doses $\left(0-20 \mathrm{~J} / \mathrm{m}^{2}\right)$ of UVC light in the presence of PBS buffer. After irradiation, the cells were incubated in fresh growth medium for an additional $48 \mathrm{~h}$. UV cytotoxicity was determined by the MTS assay (Promega). Briefly, $100 \mu \mathrm{l}$ of MTS assay solution was added to each well and incubated for $30 \mathrm{~min}$. Cell viability was determined by measuring OD at $490 \mathrm{nM}$, and four independent experiments were carried out.

\section{Big blue mouse cell line and siRNA knockdown}

BBMEFs were grown in DMEM medium containing 10\% FBS (GenDEPOT) and antibiotics. For the cll mutation assay, the cells were plated on $100-\mathrm{mm}$ plates at $50 \%$ confluence $\left(\sim 5 \times 10^{6}\right.$ cells $)$ and 500 pmoles of synthetic duplex siRNAs were transfected using $50 \mu \mathrm{l}$ of Lipofectamine 2000 reagent (Invitrogen) following the manufacturer's instructions.

\section{UV irradiation, photoreactivation, and cll mutational assays in siRNA treated BBMEFs}

$48 \mathrm{~h}$ after siRNA knockdown, the cells were washed with HBSS buffer (Invitrogen) and irradiated at $5 \mathrm{~J} / \mathrm{m}^{2}$ with UVC light, followed by photoreactivation for $3 \mathrm{~h}$ at room temperature as previously described (Yoon et al, 2009, 2010b). Fresh growth medium was added, and the cells were incubated for $24 \mathrm{~h}$. After that, the second siRNA transfection was carried out to maintain the siRNA knockdown of the target gene(s). Cells were incubated for an additional $4 \mathrm{~d}$ to allow for mutation fixation. Mouse genomic DNA was isolated using the genomic DNA isolation kit (QIAGEN). The LIZ shuttle vector was rescued from the genomic DNA by mixing DNA aliquots and transpack packaging extract (Stratagene), and the cll assay was carried out as previously described (Yoon et al, 2009, 2010b). The mutation frequency was calculated by dividing the number of mutant plaques by the number of total plaques. For mutation analysis, the sequence of PCR products of the $\mathrm{cll}$ gene from the mutant plaques were analyzed as described previously (Yoon et al, 2009, 2010b).

\section{UV-induced foci formation of Pol $\lambda$, Rev7, and Poln}

Full-length human Poln or Pol入 ORFs were cloned into the pCMV73xFlag-zeo vector (Sigma-Aldrich) and stably expressed into XPV HFs or GM637 HFs, respectively. For Rev7 foci formation, Rev7 antibody (BD Biosciences) was used for immunofluorescence in GM637 HFs. Cells were suspended and treated with siRNA and cultured on a coverslip in six-well plate with $50 \%$ confluence. After $48 \mathrm{~h}$, cells were treated with UVC $\left(30 \mathrm{~J} / \mathrm{m}^{2}\right)$. For UV irradiation, cells were washed with PBS buffer and irradiated with UVC light in the presence of PBS buffer. After irradiation, fresh growth medium was added to cells and the cells were incubated for $6 \mathrm{~h}$. After washing with PBS buffer, cells were fixed with $4 \%$ paraformaldehyde for 30 min. Fixed cells were permeabilized with $0.2 \%$ Triton $x-100$ in PBS buffer. Primary FLAG antibody (Sigma-Aldrich) or Rev7 antibody (BD Biosciences) were added to cells in PBST (0.1\% Tween 20 in PBS) containing 3\% BSA. Nuclear staining was performed with DAPI (Molecular Probe) in PBS buffer for $20 \mathrm{~min}$. The fluorescent images were visualized and captured by fluorescence microscopy (Nikon fluorescence microscope).

\section{Co-immunoprecipitation of proteins in chromatin extracts}

GM637 HFs stably expressing Flag-Pol $\lambda$ were cultured in $15 \mathrm{~cm}$ plates with $\sim 80 \%$ confluence. Cells were washed with PBS buffer and irradiated with UVC $\left(30 \mathrm{~J} / \mathrm{m}^{2}\right)$ in the presence of PBS buffer. After UV irradiation, cells were incubated in growth media for $4 \mathrm{~h}$. For chromatin bound nuclear extracts, cells were lysed with CSK (Cytoskeleton) buffer (10 mM Hepes, pH 6.8, 100 mM NaCl, 300 mM sucrose, $3 \mathrm{mM} \mathrm{MgCl}_{2}, 0.5 \%$ Triton X-100, and e-complete protease inhibitors), and chromatin extracts were treated with $1 \%$ formalin in PBS buffer for $10 \mathrm{~min}$ at room temperature followed by $125 \mathrm{mM}$ glycine addition. Cell pellets were resuspended in PBS buffer containing 30 units of Xpernase (GenDEPOT). Extracts were incubated at room temperature for $10 \mathrm{~min}$ and then centrifuged to isolate the chromatin extracts. $2 \mathrm{mg}$ of chromatin extracts were diluted with an equal volume of immunoprecipitation (IP) buffer $(150 \mathrm{mM} \mathrm{NaCl}$, Tris- $\mathrm{HCl}, \mathrm{pH} 7.5,1 \mathrm{mM}$ EDTA, 0.05\% NP40, 10\% glycerol, and protease inhibitors) and mixed with $0.5 \mu \mathrm{g}$ of FLAG agarose beads overnight at $4^{\circ} \mathrm{C}$. Flag agarose beads were washed with IP buffer twice, and bound proteins were eluted in Laemmli buffer (2\% SDS, $10 \%$ glycerol, $60 \mathrm{mM}$ Tris $-\mathrm{HCl}, \mathrm{pH}$ 6.8, $100 \mathrm{mM}$ DTT, and $0.05 \%$ bromophenol blue). PCNA ab (Santa Cruz Biotechnology), Rev 7ab (BD biosciences), or Flag ab (Sigma-Aldrich) were used for Western blot analysis.

\section{Supplementary Information}

Supplementary Information is available at https:// doi.org/10.26508/lsa.202000900.

\section{Acknowledgements}

We thank Robert Sobol (Mitchell Cancer Institute, University of South Alabama, Mobile, AL) for Pol $\lambda^{-/-}$MEFs. This work was supported by the National Institute of General Medical Sciences (R01 GM126087). 


\section{Author Contributions}

J-H Yoon: resources, data curation, software, formal analysis, validation, investigation, visualization, methodology, and writingreview and editing.

D Basu: formal analysis, investigation, and methodology.

K Sellamuthu: data curation, investigation, and methodology.

RE Johnson: data curation, formal analysis, investigation, and methodology.

S Prakash: conceptualization, formal analysis, supervision, validation, visualization, project administration, and writing-original draft, review, and editing.

L Prakash: resources, data curation, formal analysis, funding acquisition, validation, methodology, project administration, and writing-original draft.

\section{Conflict of Interest Statement}

The authors declare that they have no conflict of interest.

\section{References}

Acharya N, Johnson RE, Prakash S, Prakash L (2006) Complex formation with Rev1 enhances the proficiency of yeast DNA polymerase $\zeta$ for mismatch extension and for extension opposite from DNA lesions. Mol Cell Biol 26: 9555-9563. doi:10.1128/MCB.01671-06

Alexandrov LB, Nik-Zainal S, Wedge DC, Aparicio SA, Behjati S, Biankin AV, Bignell GR, Bolli N, Borg A, Borresen-Dale AL, et al (2013) Signatures of mutational processes in human cancer. Nature 500: 415-421. doi:10.1038/nature12477

Baynton K, Bresson-Roy A, Fuchs RP (1999) Distinct roles for Rev1p and Rev7p during translesion synthesis in Saccharomyces cerevisiae. Mol Microbiol 34: 124-133. doi:10.1046/j.1365-2958.1999.01583.x

Belousova EA, Maga G, Fan Y, Kubareva EA, Romanova EA, Lebedeva NA, Oretskaya TS, Lavrik OI (2010) DNA polymerases beta and lambda bypass thymine glycol in gapped DNA structures. Biochemistry 49: 4695-4704. doi:10.1021/bi901792c

Besaratinia A, Pfeifer GP (2006) Investigating human cancer etiology by DNA lesion footprinting and mutagenicity analysis. Carcinogenesis 27: 1526-1537. doi:10.1093/carcin/bgi311

Biertumpfel C, Zhao Y, Kondo Y, Ramon-Maiques S, Gregory M, Lee JY, Masutani C, Lehmann AR, Hanaoka F, Yang W (2010) Structure and mechanism of human DNA polymerase $\eta$. Nature 465: 1044-1048. doi:10.1038/nature09196

Braithwaite EK, Kedar PS, Lan L, Polosina YY, Asagoshi K, Poltoratsky VP, Horton JK, Miller H, Teebor GW, Yasui A, et al (2005a) DNA polymerase lambda protects mouse fibroblasts against oxidative DNA damage and is recruited to sites of DNA damage/repair. J Biol Chem 280: 31641-31647. doi:10.1074/jbc.C500256200

Braithwaite EK, Kedar PS, Stumpo DJ, Bertocci B, Freedman JH, Samson LD, Wilson SH (2010) DNA polymerases beta and lambda mediate overlapping and independent roles in base excision repair in mouse embryonic fibroblasts. PLoS One 5: e12229. doi:10.1371/ journal.pone.0012229

Braithwaite EK, Prasad R, Shock DD, Hou EW, Beard WA, Wilson SH (2005b) DNA polymerase lambda mediates a back-up base excision repair activity in extracts of mouse embryonic fibroblasts. J Biol Chem 280: 18469-18475. doi:10.1074/jbc.M411864200
Doles J, Oliver TG, Cameron ER, Hsu G, Jacks T, Walker GC, Hemann MT (2010) Suppression of Rev3, the catalytic subunit of Polろ, sensitizes drugresistant lung tumors to chemotherapy. Proc Natl Acad Sci U S A 107 20786-20791. doi:10.1073/pnas.1011409107

Garcia-Diaz M, Bebenek K, Gao G, Pedersen LC, London RE, Kunkel TA (2005) Structure-function studies of DNA polymerase lambda. DNA Repair (Amst) 4: 1358-1367. doi:10.1016/j.dnarep.2005.09.001

Garcia-Diaz M, Bebenek K, Kunkel TA, Blanco L (2001) Identification of an intrinsic 5'-deoxyribose-5-phosphate lyase activity in human DNA polymerase $\lambda$. J Biol Chem 276: 34659-34663. doi:10.1074/jbc.M106336200

Gibbs PEM, McDonald J, Woodgate R, Lawrence CW (2005) The relative roles in

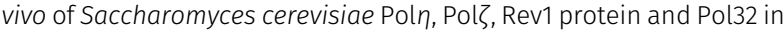
the bypass and mutation inductiion of an abasic site, T-T (6-4) photoadduct and T-T cis-syn cyclobutane dimer. Genetics 169: 575-582. doi:10.1534/genetics.104.034611

Haracska L, Unk I, Johnson RE, Johansson E, Burgers PMJ, Prakash S, Prakash L (2001) Roles of yeast DNA polymerases $\delta$ and $\zeta$ and of Rev1 in the bypass of abasic sites. Genes Dev 15: 945-954. doi:10.1101/gad.882301

Haracska L, Unk I, Johnson RE, Phillips BB, Hurwitz J, Prakash L, Prakash S (2002) Stimulation of DNA synthesis activity of human DNA polymerase K by PCNA. Mol Cell Biol 22: 784-791. doi:10.1128/ mcb.22.3.784-791.2002

Johnson RE, Haracska L, Prakash S, Prakash L (2001) Role of DNA polymerase $\eta$ in the bypass of a (6-4) TT photoproduct. Mol Cell Biol 21: 3558-3563. doi:10.1128/MCB.21.10.3558-3563.2001

Johnson RE, Prakash L, Prakash S (2006) Yeast and human translesion DNA synthesis polymerases: Expression, purification, and biochemical characterization. Methods Enzymol 408: 390-407. doi:10.1016/S00766879(06)08024-4

Johnson RE, Prakash S, Prakash L (1999) Efficient bypass of a thyminethymine dimer by yeast DNA polymerase, Poln. Science 283: 1001-1004. doi:10.1126/science.283.5404.1001

Johnson RE, Washington MT, Haracska L, Prakash S, Prakash L (2000a) Eukaryotic polymerases 1 and $\zeta$ act sequentially to bypass DNA lesions. Nature 406: 1015-1019. doi:10.1038/35023030

Johnson RE, Washington MT, Prakash S, Prakash L (2000b) Fidelity of human DNA polymerase $\eta$. J Biol Chem 275: 7447-7450. doi:10.1074/ jbc.275.11.7447

Kemmink J, Boelens R, Koning T, van der Marel GA, van Boom JH, Kaptein R (1987) ${ }^{1} \mathrm{H}$ NMR study of the exchangeable protons of the duplex d(GCGTTGCG).d(CGCAACGC) containing a thymine photodimer. Nucleic Acids Res 15: 4645-4653. doi:10.1093/nar/15.11.4645

Kikuchi S, Hara K, Shimizu T, Sato M, Hashimoto H (2012) Structural basis of recruitment of DNA polymerase zeta by interaction between REV1 and REV7 proteins. J Biol Chem 287: 33847-33852. doi:10.1074/jbc.M112.396838

Kim J-K, Choi B-S (1995) The solution structure of DNA duplex-decamer containing the (6-4) photoproduct of thymidyl $\left(3^{\prime} \rightarrow 5^{\prime}\right)$ thymidine by NMR and relaxation matrix refinement. Eur J Biochem 228: 849-854. doi:10.1111/j.1432-1033.1995.tb20331.x

Kim J-K, Patel D, Choi B-S (1995) Contrasting structural impacts induced by cis-syn cyclobutane dimer and (6-4) adduct in DNA duplex decamers: Implication in mutagenesis and repair activity. Photochem Photobiol 62: 44-50. doi:10.1111/j.1751-1097.1995.tb05236.x

Lawrence CW, Christensen RB (1978) Ultraviolet-induced reversion of cyc1 alleles in radiation -sensitive strains of yeast. I. rev1 mutant strains. J Mol Biol 122: 1-21. doi:10.1016/0022-2836(78)90104-3

Lawrence CW, Christensen RB (1979) Ultraviolet-induced reversion of cyc1 alleles in radiation-sensitive strains of yeast. III. rev3 mutant strains. Genetics 92: 397-408.

Lawrence CW, O'Brien T, Bond I (1984) UV-induced reversion of his4 frameshift mutations in rad6, rev1, and rev3 mutants of yeast. Mol Gen Genet 195: 487-490. doi:10.1007/BF00341451 
Lee J-H, Hwang G-S, Choi B-S (1999) Solution structure of a DNA decamer duplex containing the stable $3^{\prime}$ T.G base pair of the pyrimidine(6-4) pyrimidone photoproduct [(6-4) adduct]: Implications for the highly specific 3' $T \rightarrow C$ transition of the (6-4) adduct. Proc Natl Acad Sci U S A 96: 6632-6636. doi:10.1073/pnas.96.12.6632

Lee JW, Blanco L, Zhou T, Garcia-Diaz M, Bebenek K, Kunkel TA, Wang Z, Povirk LF (2004) Implication of DNA polymerase lambda in alignment-based gap filling for nonhomologous DNA end joining in human nuclear extracts. J Biol Chem 279: 805-811. doi:10.1074/jbc.M307913200

Maga G, Villani G, Ramadan K, Shevelev I, Tanguy Le Gac N, Blanco L, Blanca G, Spadari S, Hubscher U (2002) Human DNA polymerase lambda functionally and physically interacts with proliferating cell nuclear antigen in normal and translesion DNA synthesis. J Biol Chem 277: 48434-48440. doi:10.1074/jbc.M206889200

Martincorena I, Roshan A, Gerstung M, Ellis P, Van Loo P, McLaren S, Wedge DC, Fullam A, Alexandrov LB, Tubio JM, et al (2015) Tumor evolution. High burden and pervasive positive selection of somatic mutations in normal human skin. Science 348: 880-886. doi:10.1126/ science.aaa6806

Masutani C, Kusumoto R, Yamada A, Dohmae N, Yokoi M, Yuasa M, Araki M, Iwai S, Takio K, Hanaoka F (1999) The XPV (xeroderma pigmentosum variant) gene encodes human DNA polymerase $\eta$. Nature 399: 700-704. doi:10.1038/21447

Murakumo Y, Ogura Y, Ishii H, Numata S, Ichihara M, Croce CM, Fishel R, Takahashi M (2001) Interactions in the error-prone postreplication repair proteins hREV1, hREV3, and hREV7. J Biol Chem 276: 35644-35651. doi:10.1074/jbc.M102051200

Nair DT, Johnson RE, Prakash L, Prakash S, Aggarwal AK (2006) Hoogsteen base pair formation promotes synthesis opposite the 1,N6ethenodeoxyadenosine lesion by human DNA polymerase iota. Nat Struct Mol Biol 13: 619-625. doi:10.1038/nsmb1118

Nelson JR, Gibbs PEM, Nowicka AM, Hinkle DC, Lawrence CW (2000) Evidence for a second function for Saccharomyces cerevisiae Rev1p. Mol Microbiol 37: 549-554. doi:10.1046/j.1365-2958.2000.01997.x

Nick McElhinny SA, Havener JM, Garcia-Diaz M, Juarez R, Bebenek K, Kee BL, Blanco L, Kunkel TA, Ramsden DA (2005) A gradient of template dependence defines distinct biological roles for family $X$ polymerases in nonhomologous end joining. Mol Cell 19: 357-366. doi:10.1016/ j.molcel.2005.06.012

Pfeifer GP (1997) Formation and processing of UV photoproducts: Effects of DNA sequence and chromatin envirnoment. Photochem Photobiol 65: 270-283. doi:10.1111/j.1751-1097.1997.tb08560.x

Prakash S, Johnson RE, Prakash L (2005) Eukaryotic translesion synthesis DNA polymerases: Specificity of structure and function. Ann Rev Biochem 74: 317-353. doi:10.1146/annurev.biochem.74.082803.133250

Prakash S, Prakash L (2002) Translesion DNA synthesis in eukaryotes: A oneor two-polymerase affair. Genes Dev 16: 1872-1883. doi:10.1101/ gad.1009802

Pryor JM, Waters CA, Aza A, Asagoshi K, Strom C, Mieczkowski PA, Blanco L, Ramsden DA (2015) Essential role for polymerase specialization in cellular nonhomologous end joining. Proc Natl Acad Sci U S A 112: E4537-E4545. doi:10.1073/pnas.1505805112

Silverstein TD, Johnson RE, Jain R, Prakash L, Prakash S, Aggarwal AK (2010) Structural basis for the suppression of skin cancers by DNA polymerase eta. Nature 465: 1039-1043. doi:10.1038/nature09104

Washington MT, Johnson RE, Prakash S, Prakash L (2000) Accuracy of thymine-thymine dimer bypass by Saccharomyces cerevisiae DNA polymerase $\eta$. Proc Natl Acad Sci U S A 97: 3094-3099. doi:10.1073/ pnas.050491997

Washington MT, Prakash L, Prakash S (2003) Mechanism of nucleotide incorporation opposite a thymine-thymine dimer by yeast DNA polymerase $\eta$. Proc Natl Acad Sci U S A 100: 12093-12098. doi:10.1073/ pnas. 2134223100
Xie K, Doles J, Hemann MT, Walker GC (2010) Error-prone translesion synthesis mediates acquired chemoresistance. Proc Natl Acad Sci U S A 107: 20792-20797. doi:10.1073/pnas.1011412107

Xu X, Xie K, Zhang XQ, Pridgen EM, Park GY, Cui DS, Shi J, Wu J, Kantoff PW, Lippard SJ, et al (2013) Enhancing tumor cell response to chemotherapy through nanoparticle-mediated codelivery of siRNA and cisplatin prodrug. Proc Natl Acad Sci U S A 110: 18638-18643. doi:10.1073/pnas.1303958110

Yoon J-H, Bhatia G, Prakash S, Prakash L (2010a) Error-free replicative bypass of thymine glycol by the combined action of DNA polymerases $\mathrm{K}$ and $\zeta$ in human cells. Proc Natl Acad Sci U S A 107: 14116-14122. doi:10.1073/ pnas.1007795107

Yoon J-H, Lee CS, O'Connor TR, Yasui A, Pfeifer GP (2000) The DNA damage spectrum produced by simulated sunlight. J Mol Biol 299: 681-693. doi:10.1006/jmbi.2000.3771

Yoon J-H, Prakash L, Prakash S (2009) Highly error-free role of DNA polymerase $\eta$ in the replicative bypass of UV induced pyrimidine dimers in mouse and human cells. Proc Natl Acad Sci U S A 106: 18219-18224. doi:10.1073/pnas.0910121106

Yoon JH, Park J, Conde J, Wakamiya M, Prakash L, Prakash S (2015) Rev1 promotes replication through UV lesions in conjunction with DNA polymerases $\eta, 1$, and $\mathrm{k}$ but not DNA polymerase $\zeta$. Genes Dev 29: 2588-2662. doi:10.1101/gad.272229.115

Yoon J-H, Prakash L, Prakash S (2010b) Error-free replicative bypass of (6-4) photoproducts by DNA polymerase $\zeta$ in mouse and human cells. Genes Dev 24: 123-128. doi:10.1101/gad.1872810

Yoon JH, Hodge RP, Hackfeld LC, Park J, Roy Choudhury J, Prakash S, Prakash L (2018) Genetic control of predominantly error-free replication through an acrolein-derived minor-groove DNA adduct. I Biol Chem 293: 2949-2958. doi:10.1074/jbc.RA117.000962

Yoon JH, Johnson RE, Prakash L, Prakash S (2019a) DNA polymerase theta accomplishes translesion synthesis opposite 1,N(6)ethenodeoxyadenosine with a remarkably high fidelity in human cells. Genes Dev 33: 282-287. doi:10.1101/gad.320531.118

Yoon JH, McArthur MJ, Park J, Basu D, Wakamiya M, Prakash L, Prakash S (2019b) Error-prone replication through UV lesions by DNA polymerase theta protects against skin cancers. Cell 176: 1295-1309.

Yoon JH, Choudhury JR, Park J, Prakash S, Prakash L (2014) A role for DNA polymerase theta in promoting replication through oxidative DNA lesion, thymine glycol, in human cells. J Biol Chem 289: 13177-13185. doi:10.1074/jbc.M114.556977

Yoon JH, Prakash S, Prakash L (2012) Genetic control of translesion synthesis on leading and lagging DNA strands in plasmids derived from epstein-barr virus in human cells. mBio 3: 00271-00212. doi:10.1128/ mBio.00271-12

Yoon JH, Roy Choudhury J, Park J, Prakash S, Prakash L (2017) Translesion synthesis DNA polymerases promote error-free replication through the minor-groove DNA adduct 3-deaza-3-methyladenine. J Biol Chem 292: 18682-18688. doi:10.1074/jbc.M117.808659

You Y-H, Lee D-H, Yoon J-H, Nakajima S, Yasui A, Pfeifer GP (2001) Cyclobutane pyrimidine dimers are responsible for the vast majority of mutations induced by UVB irradiation in mammalian cells. J Biol Chem 276: 44688-44694. doi:10.1074/jbc.M107696200

You Y-H, Pfeifer GP (2001) Similarities in sunlight-induced mutational spectra of $\mathrm{CpG}$-methylated transgenes and the $p 53$ gene in skin cancer point to an important role of 5-methylcytosine rsidues in solar UV mutagenesis. J Mol Biol 305: 389-399. doi:10.1006/jmbi.2000.4322

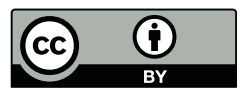

License: This article is available under a Creative Commons License (Attribution 4.0 International, as described at https://creativecommons.org/ licenses/by/4.0/). 